\title{
Liquidity Shocks in the Eurosystem Interbank Market
}

\author{
Michal Kempa \\ Hanken - Swedish School of Economics and Business Administration, \\ RUESG and HECER
}

Discussion Paper No. 203

February 2008

ISSN 1795-0562

HECER - Helsinki Center of Economic Research, P.O. Box 17 (Arkadiankatu 7), FI-00014 University of Helsinki, FINLAND, Tel +358-9-191-28780, Fax +358-9-191-28781, E-mail info-hecer@helsinki.fi, Internet www.hecer.fi 


\title{
Liquidity Shocks in the Eurosystem Interbank Market *
}

\begin{abstract}
The paper analyses the relationship between the liquidity shock variance and the size of the reserve requirement. I calibrated the key parameters of the model for the Eurosystem and found that the standard deviation of the shock is roughly $10 \%$ of the average bank's current account holding. Using these parameters and a standard interbank model, I was able to reproduce and explain the dual pattern of EONIA behaviour fairly well. In the early stage of the maintenance period, when the rate typically remains stable, it is the expectations that drive the rate, and the martingale hypothesis should hold while the liquidity effect is low. Toward the end of the maintenance period, it is the market liquidity that determines the interest rate behaviour.
\end{abstract}

JEL Classification: E52, E58, E43

Keywords: Eonia, money markets, liquidity effect.

Michal Kempa

Department of Economics

University of Helsinki

P.O. Box 17 (Arkadiankatu 7)

FI-00014 University of Helsinki

FINLAND

e-mail: michal.kempa@helsinki.fi

* The research was supported by OP-ryhmän Tutkimussäätiö. 


\title{
Liquidity Shocks in the Eurosystem Interbank Market
}

\author{
Michal Kempa *
}

\section{Introduction}

European Central Bank control over inflation in the Eurosystem is based on the power to affect interest rates in the economy. In practical terms the attention is focused on the average transaction rate in the interbank market, which is later used as a benchmark for loans and deposits of commercial institutions. How the Central Bank tools can affect the interbank market is then the central issue for the effectiveness of the monetary policy implementation and the topic of this paper.

Analysing the main features of the money market might suggest that the Central Bank has a near complete control. Commercial banks need funds to process and facilitate transactions performed by their customers every day. In addition, they need to satisfy the reserve requirement and are not allowed any overdraft on their account in the Central Bank. Available sources of liquidity, which include open market operations and standing facilities, are directly controlled by the Central Bank. Closer inspection, however, reveals areas where that control is not so tight: banks need to maintain an average value of funds on their account, meaning they might chose to keep less one day and compensate later on. This can have very important consequences (first pointed out by Hamilton (1996) as the so-called martingale hypothesis): If there were no additional barriers to trade, the current rate must be the same as the expected rate in the future in order to prevent arbitrage opportunities. In that case, however, the interest rate is determined by the market expectations rather than by liquidity controlled by the Central Bank.

The martingale hypothesis was initially rejected by Hamilton (1996), who attributed the deviation to the trading costs. More recent econometric papers by Moschitz (2004), Würtz (2003) (for Eurosystem) and Thornton (2001) (for

*University of Helsinki, RUESG, michal.kempa@helsinki.fi. I would like to thank Nuno Cassola, Flemming Würtz, Rune Stenbacka, Erkki Koskela and Tuomas Välimäki for their helpful comments and suggestions. The research was supported by OP-ryhmän Tutkimussäätiö. 
the USA) fail to find evidence against this hypothesis for most of the days of the maintenance period. However, the same researchers find that the market liquidity becomes an important determinant of the interbank interest rate on the last days of the maintenance period.

The theoretical contributions include models of Pérez-Quirós and RodríguezMendizábal (2006), Välimäki (2003), Clouse and Dow Jr. (2002) and Bartolini et al. (2001) that focus on explaining the increase in the average level of the interest rate and interest rate volatility at the end of the maintenance period without using trade barriers. The models are constructed in a very similar way and all include so-called liquidity shock as defined initially by Poole (1968). This term captures all the liquidity flows that were not anticipated by a commercial bank when it was deciding on its borrowing value in the interbank market. One example might be a late transaction request received after the trading day is over.

From the banks' perspective, such liquidity shocks introduce a costly randomness into the final end of the day current account balance that is, in turn, used to satisfy the obligatory reserve requirement. Consider, for example, a situation where a positive liquidity shock causes the bank account to exceed the remaining part of reserve requirement for this maintenance period. Any excess funds must then be deposited at the penalty rate, which is significantly below the market rate. To avoid such an expensive operation, banks need to make sure the current account before the shock realisation remains at the appropriate level. Pérez-Quirós and Rodríguez-Mendizábal (2006) show that this can result in additional incentives for, so-called, back-loading. ${ }^{1}$ If all banks share similar incentives, the liquidity becomes more valuable at the end of the maintenance period, which might explain the pattern in the interest rate behaviour that was observed in many interbank markets in the late 90s.

Even though the liquidity shock is a central issue in most of the papers on the interbank market, its properties have not been properly analysed thus far. In fact, to the author's knowledge, there has not been any attempt to estimate the statistical parameters based on actual market data. Also, there is no paper that clearly compares the behaviour of the models using significantly different shock realisations. In this paper, I address these issues.

The contribution of this paper is two-fold. First, I present a calibration of the size of the liquidity shock based on actual Eurosystem money market data. Second, I show that the magnitude of the shock compared to the current account balance determines the results of standard models. The combination of these two observations can then be used to explain the behaviour of the interbank interest rate during the maintenance period.

These results have direct and important consequences for the implementa-

\footnotetext{
${ }^{1}$ Back-loading bank postpones satisfaction of the reserve requirement until the later part of the maintenance period by keeping the current account value below the average level required.
} 
tion of the monetary policy. For the majority of the maintenance period, the interest rate is linked to the expected level on the settlement day and the days preceding it, and changes in liquidity (so-called liquidity effect) have little impact. Market liquidity, however, determines the level of the interest rate on the last days of the maintenance period, which can be used by the Central Bank to control the expectations. These findings are in line with the econometric analyses performed by Würtz (2003) and Moschitz (2004).

In section 2, I start with a general discussion on the interbank market by describing the components of the demand and supply of funds.

In section 3, I use a modified version of the standard Poole (1968) model based on Pérez-Quirós and Rodríguez-Mendizábal (2006) and Kempa (2006). I show that the equilibrium interest rate depends on the probabilities of using standing facilities and the so-called dynamic cost factor that captures the relative cost to early satisfy the reserve requirement. I also show the limitations of the theoretical model that justify the use of simulations later on in the paper.

In section 4 , I use the data obtained from the ECB to calibrate the volatility of the shock, which turns out to be a critical parameter. I find that the standard deviation of the shock is very small and around $10 \%$ of the average current account holdings. This means that the banks face only minor risks.

Section 5 contains the theoretical portion of the paper. I show how the behaviour of the model changes when I use different values of the shock distribution parameters. I show that there exists a flat part in the demand schedule where borrowing cannot be uniquely determined under risk neutrality. The range of the flat schedule changes on different days of the maintenance period and essentially disappears when the remaining part of the reserve requirement drops below $6 * \sigma$, where $\sigma$ is the standard deviation of the liquidity shock. This suggests that the interest rate will follow the martingale process for the majority of the maintenance period and might only deviate shortly before the settlement day (when the remaining required reserves drop low).

Finally, in section 6, I simulate the behaviour of the market under several different scenarios using the calibrated parameters. I find confirmation for the theoretical results from the previous section; it seems that the interest rate follows the martingale hypothesis for all but the last days of the maintenance period, lending strong support to the results obtained by Moschitz (2004) and Würtz (2003). Section 7 concludes.

\section{The interbank market in the Eurosystem}

This section introduces some of the key features of the interbank market that constitute the basis of the model derived later on. I also present several stylised facts that can be explained using the model.

The role of the short-term (typically overnight) interbank market is to re- 
distribute the available liquidity among its participants. The liquidity takes the form of deposits at the Central Bank and is used to settle transactions between the commercial banks and to satisfy the obligatory reserve requirement. The reserve requirement is implemented in the form of a so-called averaging provision. This means that banks are required to maintain an average for the current account over a certain period of time, referred in the text as the maintenance period.

The average transaction rate is used as the benchmark for other rates in the economy and remains the main operating target of the Central Bank. The market, as a whole, is subject to aggregate liquidity changes resulting from transactions such as cash withdrawals that require the exchange of some portion of the Central Bank deposits for banknotes and coins. The factors that affect aggregate liquidity and that are not directly controlled by the Central Bank are, in the literature, referred to as autonomous liquidity factors.

\subsection{Interbank interest rate}

\subsection{Aggregate liquidity}

The supply of aggregate liquidity remains at the Central Bank discretion. Once the aggregate liquidity is settled during the open market operations, its balance can only be altered by changes in the autonomous liquidity factors (ALF). These include, for example, cash, government accounts and other elements of the base money that are not controlled directly by the Central Bank. The ability to predict these changes is typically one of the main concerns of the Central Bank, which uses the aggregate liquidity to affect the interbank rate. Even though sophisticated and accurate tools were developed to forecast such changes, policy design occasionally limits the ability to fully accommodate them. For instance, in the Eurosystem, the main refinancing operations are performed only once a week, while changes to ALF take place every day. Therefore, the market liquidity might and will deviate (at least for a short time) from the Central Bank's target level.

The degree to which the aggregate change in the liquidity will influence the interest rate is signified by the liquidity effect and can be well assessed using econometric methods. A common approach involves regressing changes in the market rate on the aggregate imbalance measured by the the net recourse to standing facility. Studies done by Würtz (2003) and Moschitz (2004) for the Eurosystem data show that the effect is only present in the last two days of the maintenance period. My own calculations, based on the publicly available data for the period March 2004 - April 2006, return an estimate for the liquidity effect on the last day of the maintenance period at 0.0754 (a EUR 1B imbalance results in a rate change of 7 basis). Similar studies by Hamilton (1997) and Thornton (2001) for the US markets also find little evidence of the effect. 


\subsection{Individual liquidity and liquidity shock}

The demand for reserves by the commercial banks is determined first by the obligatory reserve requirement and, second, by their balance of transactions with other market participants. The reserve requirement is known in advance at the start of the maintenance period. The balance of transactions can typically be estimated quite accurately by the bank itself based on past time experiences. For example, a large mortgage bank can predict substantial inflows of liquidity on days when its customers are making loan repayments.

Even though the forecasts might be quite accurate, there is still some uncertainty that banks need to account for. It stems primarily from:

- late transactions (finalised after the trading day is over) or errors in transaction processing

- market imperfections preventing the bank from obtaining the desired liquidity.

The effect from later transactions is fairly straightforward but less significant in developed markets. Historically, when the information technology was barely developed, the transactions between banks' customers were processed in clearing sessions. Sometimes, the outcome of the session was announced after trade was concluded (or close to the end of the trading day). In this case, banks that needed liquidity to cover the balance of payments of their customers had no way of obtain the funds on the market and had to resort to the Central Bank facilities. Nowadays, with the RTGS systems ${ }^{2}$ in place, this problem might have be less severe.

The effect of market imperfections could result from certain situations when a commercial bank's ability to trade is hindered by external factors. For example, uncertainty about the bank's financial condition might result in the restrictions of funds available for trade in the form of credit lines. Some banks obtain the majority of their funding through unsecured borrowing from a selected group of banks, which form a so-called trading group. If the trade between different trading groups is restricted, even though the total market liquidity is sufficient to satisfy the reserve requirement, some banks will find themselves short and others with surplus funds.

The examples given above concern the individual bank balances but not the aggregate liquidity. However, it is also possible that the bank will face an unexpected transaction that will also have an impact on the aggregate market liquidity. For example, a surge in cash withdrawals might force several banks to exchange excess portion of their deposits for banknotes and coins. All aggregate changes are, however, closely watched by the Central Bank and in case of the ECB they are offset during open market operations. This allows me to focus

\footnotetext{
${ }^{2}$ Real Time Gross Settlement
} 
mainly on the idiosyncratic sources of errors in liquidity forecasts.

From a commercial bank's perspective, the effects of late transactions and market imperfections are, in fact, similar and constitute a random deviation between the current account balance at the end of the day and the expected level. This motivates their combined modelling, and, in this paper I refer to them as liquidity shocks. In the remaining part of this section, I discuss the various statistical properties and theoretical assumptions required for liquidity shock modelling.

\subsection{Modelling liquidity shock}

The liquidity shock, denoted as $\varepsilon_{t}$ for the remainder of the paper, is the key element of the model. If all banks could perfectly predict their current account balances, no buffer would be necessary for the purpose of averaging the reserve requirement. ${ }^{3}$ Some of the modelling assumptions need, however, a bit of explanation.

First, as noted before, I have chosen to focus on individual sources of uncertainty rather than aggregate ones. In practice, I assume that the Central Bank compensates for changes in the autonomous liquidity factors (which affect the total market liquidity) on a daily basis, even though, in reality, the operations take place once a week.

Second, I assume the shock is identically and independently distributed. I assume a normal distribution with an expected value equal to zero and the standard deviation $\sigma$. A zero mean reflects the fact that that the banks do not expect the shock to be biased toward neither a surplus nor a shortage of liquidity. There might be a pattern in the actual market that would link some bank characteristics with expected liquidity shocks. For instance, large banks tend to be net liquidity borrowers, which might suggest that the liquidity shock they face would be, on average, negative. However, due to the lack of available data, I am unable to perform a thorough analysis on that issue, and for the remainder of the paper, I simply assume a symmetric distribution.

The value of $\sigma$ is calibrated in section 4.1. I assume the standard deviation of the liquidity shock to be proportional to the size of the bank as measured by the average Central Bank account balance. This might require some justification.

On one hand, it is quite sensible to assume that large banks with a sizable consumer base, involved in multiple complicated operations are subject to a larger absolute amount of errors in transaction processing and a larger

\footnotetext{
${ }^{3}$ Averaging reserve requirement means that the banks have to satisfy an average reserve requirement within the maintenance period, but are free to chose their daily values. That means, that random deviation from the target assigned by the Central Bank will not force the immediate use of the standing facilities provided that the bank can compensate for this in the following days.
} 
number of later transactions. In addition, large banks are more likely to run into problems with market depths, especially if the trading groups they operate with are small and unable to satisfy their demand for liquidity (or alternatively absorb surpluses). On the other hand, large banks can probably afford more staff, whereby the transactions would be handled more carefully, and liquidity flows would be more accurately predicted with the ultimate result that fewer errors would be made. It is, however, unlikely that those benefits will be able to fully compensate for the scale of their operations, hence, the liquidity shock and corresponding liquidity shock variance are likely to linked to the bank size.

\section{The model}

This section presents an overview of the model of the interbank market, which constitutes the basis of the simulation study in section 6 . The setup of the model can already be considered standard and has been extensively described, for example, in Poole (1968), followed by Hamilton (1996) and, more recently, Pérez-Quirós and Rodríguez-Mendizábal (2006), Välimäki (2003) and Bartolini et al. (2001), as well as my own papers.

The model illustrates the behaviour of the individual bank in the interbank market with the averaging reserve requirement provision regime. Each bank has the obligatory reserve requirement, initial assets (assumed to be just sufficient to satisfy the requirement) and the decision regarding how to use them. Some liquidity can be lent to other banks and the remainder will be stored in the Central Bank's current account and will contribute to the reserve requirement. The bank can also borrow the funds from the market if such is found to be profitable.

The timing of events in the model for each day of the maintenance period is as follows:

$$
\stackrel{m_{t}, d_{t} \quad b_{t} \quad \varepsilon_{t} \quad m_{t+1}, d_{t+1}}{\longrightarrow}
$$

The bank starts the day with assets $m_{t}$ and a deficiency $d_{t}$ from the previous day. It can lend out the assets or acquire more through interbank borrowing represented by the term $b_{t}$, which can also be interpreted as a simple demand for liquidity at market rate. The liquidity shock, $\varepsilon_{t}$, was explained in more detail in the previous section. It signifies the random effects that the commercial bank is unable to foresee or counter which will ultimately affect its end-of-the-day current account value. I assume the shocks to be independently and identically distributed with a zero mean and a standard deviation $\sigma$.

These three factors contribute to the final end of day current account balance $m_{t}+b_{t}+\varepsilon_{t}$ (a negative $b_{t}$ would mean that the bank is lending).

The last term, deficiency $d_{t}$, represents the remaining portion of the reserve requirement to be satisfied, and follows a simple equation of motion: 


$$
\begin{gathered}
d_{1}=R=m_{1} * T \\
d_{t}=\left\{\begin{array}{ccc}
d_{t-1} & \text { if } & m_{t}+b_{t}+\varepsilon_{t}<0 \\
d_{t-1}-m_{t}-b_{t}-\varepsilon_{t} & \text { if } & 0<m_{t}+b_{t}+\varepsilon_{t}<d_{t-1} \\
0 & \text { if } & m_{t}+b_{t}+\varepsilon_{t}>d_{t-1}
\end{array}\right.
\end{gathered}
$$

where $R$ is the exogenously given value of the reserve requirement set by the Central Bank (equal to the daily requirement multiplied by the number of days in the maintenance period). I assume that the bank's starting assets are sufficient to satisfy that requirement. ${ }^{4}$ I provide the following explanation for eq.(1). On day 1 , the bank receives information about the average value of the reserve requirement for the maintenance period, which is equal to its initial assets $m_{1}$. This means that during $T$ days, the total value of the current account balances needed to satisfy the requirement is $m_{1} * T$.

At the end of day 1 , the bank will have the current account balance $m_{1}+$ $b_{1}+\varepsilon_{1}$ which will be used to satisfy some part of the reserve requirement. At the start of day 2 , the remaining part of the deficiency is $d_{1}-m_{1}-b_{1}-\varepsilon_{1}$. The end-of-the-day balance might also be less than zero, in which case no reserve requirement is satisfied, or the balance is sufficient for the entire requirement to be satisfied.

The bank's problem is to minimise the borrowing cost by choosing an appropriate value for $b_{t} \cdot{ }^{5} \mathrm{~A}$ bank's performance in one maintenance period does not affect another maintenance period, hence, the problem concerns a finite number of days. That also means that the solution has a different structure in the last day of the reserve maintenance period and for the days preceding it, which is shown (and explained) in the following part.

\section{$3.1 \quad$ Time $\mathrm{T}$}

The problem concerning the last day of the maintenance period is indeed the same for any case without an averaging provision reserve requirement regime and was already solved by Poole (1968).

For the last day of the maintenance period, $t=T$ the bank must only satisfy the remaining part of the reserve requirement. Since interbank loans have one period maturity, and no deficiency is carried over to next maintenance period,

\footnotetext{
${ }^{4}$ The ECB uses the term benchmark allotment to describe how much total liquidity is needed every day to satisfy the reserve requirement. This value is usually targeted during open market operations, so the market is left with no aggregate surplus or shortage of liquidity.

${ }^{5}$ In practice, the bank obtains its liquidity from either bidding in open market operations or interbank borrowing but, I do not differentiate between these two. This assumption is not particularly restrictive. In fact, it is sufficient to assume that the expected tender rate is equal to the expected interbank rate, which can be easily argued with a simple arbitrage argument. Hence, the funds obtained during liquidity tenders should be perfect substitutes for the funds obtained through interbank borrowing.
} 
this is a single period problem. The bank minimises the cost of obtaining funds to cover a potential liquidity shock:

$$
V_{T}=\min _{b_{T}} i_{T} b_{T}+E\left(c_{T}\right)
$$

where $i_{T} b_{T}$ stands for the cost of borrowing (for a negative $b_{T}$, the bank is the net lender). $E\left(c_{T}\right)$ denotes the expected cost of using the standing facilities (occurring whenever the account value is different from the reserve requirement) given by

$$
\begin{gathered}
E\left(c_{T}\right)=i^{l}\left[\int_{-\infty}^{-m_{T}-b_{T}+d_{T}}\left(-m_{T}-b_{T}+d_{T}-\varepsilon_{T}\right) f\left(\varepsilon_{T}\right) d \varepsilon_{T}\right]- \\
i^{d}\left[\int_{-m_{T}-b_{T}+d_{T}}^{\infty}\left(m_{T}+b_{T}-d_{T}+\varepsilon_{T}\right) f\left(\varepsilon_{T}\right) d \varepsilon_{T}\right],
\end{gathered}
$$

where $f(\varepsilon)$ denotes the density function of the shock and $i^{l}, i^{d}$ are the lending and deposit facility respectively. Equation (4) means that a shock $\varepsilon_{T}$ realisation higher (lower) than the account balance $m_{T}+b_{T}-d_{T}$ forces the use of a deposit (lending) facility at rate $i^{d}\left(i^{l}\right)$. The first order conditions associated with problem (3) provide a well-known result: ${ }^{6}$

$$
i_{T}=i^{l} F\left(-m_{T}-b_{T}+d_{T}\right)+i^{d}\left(1-F\left(-m_{T}-b_{T}+d_{T}\right)\right) .
$$

At the optimal volume of borrowing, the probability weighted cost of using standing facilities is equal to the cost of obtaining funds in the market.

For the interest rate in the middle of the interest rate corridor ${ }^{7}$, the aggregate market liquidity $M_{T}$ and aggregate deficiency $D_{T}$ make it possible to solve eq.(5) to obtain the equilibrium condition:

$$
F\left(-M_{T}+D_{T}\right)=0.5
$$

which for the symmetric distribution of shocks implies

$$
M_{T}=D_{T} .
$$

This result is used by the central bankers that attempt to set the value of the aggregate market liquidity in their operations in order to control the level of the interest rate on the last day of the maintenance period. ${ }^{8}$

An interesting observation can be made by analysing the derivatives of the value function:

$$
\frac{\partial V_{T}}{\partial m_{T}}=-i_{T}
$$

and

$$
\frac{\partial V_{T}}{\partial d_{T}}=i_{T}
$$

\footnotetext{
${ }^{6}$ As shown in Appendix B.

${ }^{7}$ Equal to $i_{t}=\frac{\beta^{l}+i^{d}}{2}$.

${ }^{8}$ The ECB refers to that value as benchmark liquidity.
} 
The equations first show that the additional deficiency and assets are perfect substitutes on the last day of maintenance period. Intuitively, it does not matter for the bank whether it arrives at the last day with one extra euro on the current account or the remaining reserve requirement one euro smaller. The value of that additional euro is simply equal to the market price at which it can be lent (or borrowed) in the market.

\subsection{Periods $\mathrm{t}<\mathrm{T}$}

On the days before the end of the maintenance period, the commercial banks' borrowing value also has an effect on the remaining part of the deficiency that needs to be satisfied in the maintenance period. The problem thus becomes dynamic and can be illustrated by Bellman's equation:

$$
V_{t}=\min _{b_{t}}\left\{i_{t} b_{t}+E_{t}\left(c_{t}\right)+E_{t}\left(V_{t+1}\right)\right\} .
$$

Solving the problem for optimal borrowing results in the following equilibrium conditions: ${ }^{9}$

$$
i_{t}=\underbrace{i^{l} F\left(-b_{t}-m_{t}\right)}_{1 .}+\underbrace{i^{d}\left[1-F\left(d_{t}-b_{t}-m_{t}\right)\right]}_{2 .}-\underbrace{\int_{-m_{t}-b_{t}}^{d_{t}-b_{t}-m_{t}} \frac{\partial V_{t+1}}{\partial d_{t+1}} f\left(\varepsilon_{t}\right) d \varepsilon_{t}}_{3 .} .
$$

Here, the interest rate is the probability weighted average of three terms, each of them with a specific interpretation. Term 1 reflects the expected cost of the shock (negative) falling below the bank's assets, thus forcing it to use the lending facility. Term 2, in a similar fashion, reflects the cost of the shock that exceeds the current deficiency and forces the bank to use the deposit facility. Finally, the last term gives the value required to satisfy only part of the reserve requirement and to carry over the deficiency to the next period.

The last term (sometimes called the dynamic cost factor in literature and in this paper) depends on the derivative of the value function that is given by the following equation:

$$
\frac{\partial V_{t}}{\partial d_{t}}=\underbrace{-i^{d}\left[1-F\left(d_{t}-b_{t}-m_{t}\right)\right]}_{1 .}+\underbrace{\int_{-\infty}^{d_{t}-b_{t}-m_{t}} \frac{\partial V_{t+1}}{\partial d_{t+1}} f\left(\varepsilon_{t}\right) d \varepsilon_{t}}_{2} .
$$

In practice, the cost of carrying over an additional unit of deficiency depends on whether the bank is locked-in, that is, all the deficiency is satisfied. If this is the case, extra funds must be deposited at the Central Bank interest rate $i^{d}$ (term 1), otherwise the extra unit will simply be carried into another period

\footnotetext{
${ }^{9}$ As shown in Appendix $\mathrm{C}$
} 
(term 2).

A demand schedule based on the equation (11) is illustrated in Figure 1. Note, that some parts of the figure are flat, which means that the demand for liquidity, at certain interest rate levels, is not uniquely determined. More details and exact interpretation of the shape will be included in the latter part of the paper, in section 5.1.

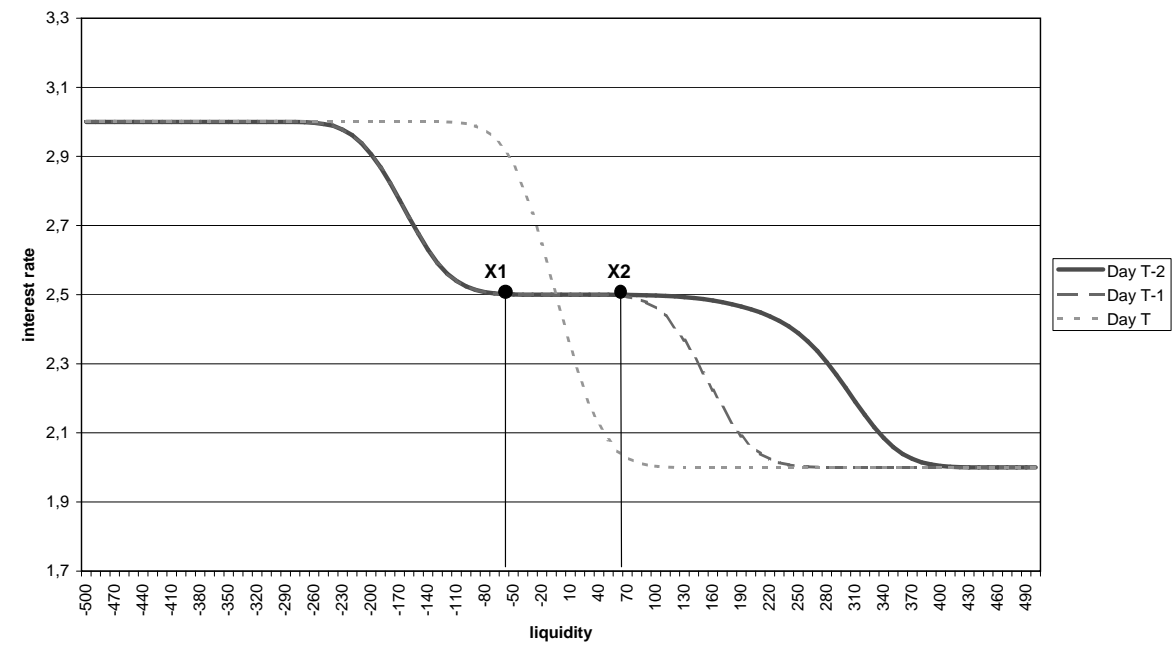

Figure 1: 3-day maintenance period

\subsection{Example: reserve maintenance period with 3 days}

In this example, I am going to show how the model can be used to analytically calculate the individual bank demand for liquidity under the assumption that the expected rate is equal to the Central Bank's target set in the middle of the standing facilities corridor ${ }^{10}$.

\footnotetext{
${ }^{10}$ The corridor is defined by standing facility rates. The Central Bank promises to accept any values of deposits at its lower boundary $\left(i^{d}\right)$, and similarly grants unlimited loans at its
} 
Due to the recursive structure of the problem, I start the solution from the last day of the RMP.

Day 3

On day 3, I have the same solution as in section 3.1. The market clearing rate equals (5):

$$
i_{3}=i^{l} F\left(-m_{3}-b_{3}+d_{3}\right)+i^{d}\left(1-F\left(-m_{3}-b_{3}+d_{3}\right)\right)
$$

and the liquidity, which holds the rate at the middle of the interest rate corridor, is given by the following relationship

$$
m_{3}+b_{3}=d_{3} .
$$

For the interest rate to stay in the middle of the corridor, the market should have just enough liquidity to satisfy the reserve requirement.

The derivative of the value function is then $\frac{\partial V_{3}}{\partial d_{3}}=-i_{3}$ with the same interpretation as in section 3.1.

Day 2

On day 2, I can use the fact that the future value function derivative is fixed for all banks regardless of their assets, hence for each bank:

$$
\begin{aligned}
i_{2}=i^{l} F\left(-b_{2}-m_{2}\right)+i^{d}\left[1-F\left(d_{2}-b_{2}-\right.\right. & \left.\left.m_{2}\right)\right] \\
& +\int_{-b_{2}-m_{2}}^{d_{2}-b_{2}-m_{2}} E\left(i_{3}\right) f\left(\varepsilon_{2}\right) d \varepsilon_{2}
\end{aligned}
$$

so

$$
\begin{aligned}
i_{2}=i^{l} F\left(-b_{2}-m_{2}\right)+i^{d}[1 & \left.-F\left(d_{2}-b_{2}-m_{2}\right)\right] \\
& +E\left(i_{3}\right)\left[F\left(d_{2}-b_{2}-m_{2}\right)-F\left(-b_{2}-m_{2}\right)\right] .
\end{aligned}
$$

This has a similar interpretation as in section 3.2.

I assume that the expected interest rate in the last period $E\left(i_{3}\right)$ is equal to the Central Bank target in the middle of the corridor system. The condition at which the market actually clears at the target rate is given by: ${ }^{11}$

$$
m_{2}+b_{2}=\frac{d_{2}}{2} .
$$

This is an intuitive result that indicates that half of the remaining reserve requirement should be satisfied in order for the interest rate to remain in the middle of the corridor system. The derivative of the value function takes the following form for each individual bank:

$$
\frac{\partial V_{2}}{\partial d_{2}}=-i^{d}\left[1-F\left(d_{2}-b_{2}-m_{2}\right)\right]-E\left(i_{3}\right) F\left(d_{2}-b_{2}-m_{2}\right) .
$$

upper boundary $\left(i^{l}\right)$, thus rendering any transactions outside that range unfeasible. In the Eurosystem, the corridor is symmetric around a target rate.

${ }^{11}$ As shown in Appendix D 
Unless deficiency $d_{2}$ is significantly larger than the current account $m_{2}$ (so $\left.F\left(d_{2}-b_{2}-m_{2}\right)=1\right)$, this expression is going to take a different value for each individual bank, thus rendering the aggregation process more complicated and intractable.

Day 1

The analytical solution for this period is not possible without further assumptions. To illustrate this fact, I use equation (11) once again. Substituting (18) for $\frac{\partial V_{2}}{\partial d_{2}}$ yields the following relationship at the equilibrium rate:

$$
\begin{aligned}
& i_{1}=i^{l} F\left(-b_{1}-m_{1}\right)+i^{d}\left[1-F\left(d_{1}-b_{1}-m_{1}\right)\right]- \\
& \int_{-b_{1}-m_{1}}^{d_{1}-b_{1}-m_{1}}\left[-i^{d}\left[1-F\left(d_{2}-m_{2}-b_{2}\right)\right]-E\left(i_{3}\right) F\left(d_{2}-m_{2}-b_{2}\right)\right] f\left(\varepsilon_{1}\right) d \varepsilon_{1},
\end{aligned}
$$

which can be further simplified using (17):

$$
\begin{aligned}
i_{1}=i^{l} F(- & \left.b_{1}-m_{1}\right)+i^{d}\left[1-F\left(d_{1}-b_{1}-m_{1}\right)\right] \\
& +\int_{-b_{1}-m_{1}}^{d_{1}-b_{1}-m_{1}}\left[-i^{d}\left[1-F\left(d_{2} / 2\right)\right]-E\left(i_{3}\right) F\left(d_{2} / 2\right)\right] f\left(\varepsilon_{1}\right) d \varepsilon_{1} .
\end{aligned}
$$

The first two terms look familiar and have the same interpretation as above. The value of the dynamic cost factor depends, however, on the deficiency $d_{2}$, which, in turn, is determined by the liquidity shock realisation. This means that the analytical solution is no longer possible without distribution function assumptions. This motivates the use of the numerical tools presented in section 6.

\subsection{Summary}

In this section, I have introduced a model of the interbank market in which an averaging provision is utilised and the banks are subject to liquidity shocks. The model, based on Poole (1968), Välimäki (2003) and Pérez-Quirós and RodríguezMendizábal (2006), links the equilibrium interest rate with the demand for liquidity. At optimal borrowing, the cost of financing from the market (given by interest rate $i_{t}$ ) is equal to the expected cost of financing with standing facilities in the future.

In the latter part of this section, I also show how the model can be used to demonstrate the demand for liquidity for the last two days of the maintenance period and the limitations that make the analytical solution for the preceding days intractable. This motivates the use of numerical methods in section 6 for the purpose of simulating the behaviour of the market. 


\section{Calibration of the parameters for the Eurosys- tem}

\subsection{Liquidity shock estimation}

In this section, I show the procedure and results for the calibration of the liquidity shock properties. The key parameter is the standard deviation $\sigma$ of the liquidity shock. If the shock volatility is low, the commercial banks using the market could plan the path of the reserve requirement well in advance to avoid any use of the facilities. A high volatility of the shock means their forecasts are prone to errors, and recourses to the standing facilities are likely and need to be taken into consideration. As discussed in section 2.4 , I assume the volatility of the shock is related to the bank size, hence, my focus is on the estimation of that relationship.

To accomplish that goal, I have gathered the following data ${ }^{12}$ for $N=86$ selected banks covered by the reserve requirement in the Eurosystem, for each day during the period 24 January 2004 - 31 May 2005:

1. Current account value at the end of the day

2. The use of standing facilities

3. The reserve requirement applicable for the relevant maintenance period

The information was provided by National Central Banks, and includes a number of banks of different sizes from each country (see table 1). In addition, I have obtained an extended sample (including the year 2003) for all the banks except for Germany. The results with the extended period (but without Germany) were very similar to the ones presented below; hence, for the remainder of the paper, I use a shorter but broader sample.

The results of the calibration are presented in Table 2. In the remaining part of the section, I will explain the calculation procedure and interpret the value of the parameters.

First of all, we recall that the liquidity shock occurs after trade is no longer possible and constitutes an error in the current account forecasts. Hence, if I knew the target current account value for a sample bank, I could compare it to the actual realisation and the difference attribute to the shock. This is difficult to perform during the maintenance period, when banks might choose different paths for the reserve requirement, depending on their individual expectations for the interest rate evolution or other motives such as risk aversion. However, on the last day of the maintenance period, any cost-minimising bank avoiding costly standing facilities would simply target the current account balance that is

\footnotetext{
${ }^{12}$ The data were obtained during an internship at the ECB during the period April - June 2006. I am very grateful to the ECB for the access to the data and all help provided during this period.
} 


\begin{tabular}{|c|c|c|}
\hline & Country & Number of banks \\
\hline \hline 1 & Germany & 15 \\
\hline 2 & France & 12 \\
\hline 3 & Spain & 12 \\
\hline 4 & Italy & 11 \\
\hline 5 & Belgium & 6 \\
\hline 6 & Netherlands & 7 \\
\hline 7 & Ireland & 4 \\
\hline 8 & Finland & 4 \\
\hline 9 & Luxembourg & 3 \\
\hline 10 & Greece & 3 \\
\hline 11 & Portugal & 4 \\
\hline 12 & Austria & 5 \\
\hline & Total & 86 \\
\hline
\end{tabular}

Table 1: Sample Banks

\begin{tabular}{|l|l|l|l|}
\hline & $\begin{array}{l}\text { Liquidity } \\
\text { shock }\end{array}$ & $\begin{array}{l}\text { Aggregate shock } \\
\text { volatility }\end{array}$ & Current account \\
\hline \hline mean & -1.5 & -247.8 & 764.9 \\
\hline $\begin{array}{l}\text { standard devia- } \\
\text { tion }\end{array}$ & 66.5 & $1,740.1$ & 966.4 \\
\hline
\end{tabular}

Table 2: Liquidity shock for the sample

Liquidity shock: net recourse to the standing facilities and excess over the reserve requirement on the last days of the maintenance period.

Aggregate shock: sum of the net recourse to the standing facilities and excess over the reserve requirement for the whole sample.

Current account: individual bank's deposit.

All data in EUR Millions. 
equal to the remaining value of the reserve requirement. That gives me enough information to compute the liquidity shock for those days. The sample covers 15 maintenance periods, thus providing 15 realisations of liquidity shock for each individual bank.

The exact procedure to calculate the shock value is fairly straightforward. I have the data on each bank's end of the day current account balance after the use of the standing facilities. This balance, according to the bank regulations, for the last day of the maintenance period, must not be lower than the remaining deficiency.

I also have the data on the use of the standing facilities (included in the final current account balance), so I am able to compute the current account value directly after the liquidity shock realisation.

Linking this data to the theory presented in section 3 results in the following relationship:

$$
\begin{array}{r}
(\text { final current account })_{i t}-(\text { net recourseto standing facilities })_{i t}= \\
m_{i t}+b_{i t}+\varepsilon_{i t} .
\end{array}
$$

From the available data, I can also compute how much of the reserve requirement each bank has satisfied earlier in the period. That corresponds to term $d_{i t}$ from section 3. According to formula (14), a cost minimising bank would target the current account value equal to the remaining deficiency.

$$
m_{i t}+b_{i t}=(\text { deficiency })_{i t}
$$

This can then be substituted into eq.(21) to obtain an estimate for the liquidity shock $\varepsilon_{i t}$ :

$$
\begin{aligned}
& \varepsilon_{i t}=\left(\text { final current account }_{)_{i t}-}\right. \\
& \quad-(\text { net recourse to standing facilities })_{i t}-(\text { deficiency })_{i t}
\end{aligned}
$$

Index it indicates the realisation for bank $i$ on day $t$. The other statistics from the Table 2 are straightforward. The top entry in the first column gives the average liquidity shock across all banks included and periods and is computed as:

$$
\frac{1}{N T} \sum_{i}^{N} \sum_{t}^{T} \varepsilon_{i t},
$$

where $\varepsilon_{i t}$ is a single shock realisation for bank $i$ at time $t$. The standard deviation reported in the second column is computed as the average standard deviation across all banks included:

$$
\frac{1}{N} \sum_{i}^{N} S E_{i},
$$


where $S E_{i}$ is the standard deviation of the liquidity shock for bank $i$.

In order to compute the aggregate shock, I have added up the shocks of all the banks in the sample. In the last column, I have included the average current account value I used as an approximation of the bank size. Large banks, with a wide scale of operations, are likely to have a higher reserve requirement base and, hence, maintain a higher current account value.

Is the liquidity shock significant in the Eurosystem in light of the results from Table 2? Compared to the daily current account value, the shock does not seem to be substantial enough (the next section concentrates on that link a bit more) to constitute a serious threat of overdraft to the commercial bank. Unless the bank decides to satisfy the reserve requirement prematurely, the possibility of a positive shock large enough to force the use of the deposit facility seems even lower. This means, however, that the probability of using the standing facilities during the maintenance period is negligible, an issue further covered in the next section.

Any estimates of the liquidity shock for the Eurosystem should be approached with care due to the existence of previously mentioned excess reserves $^{13}$. While the model predicts that any excess liquidity will be deposited, this is often not the case in reality. This has profound consequences for the efficient determination of the liquidity supply. It is not just sufficient to calculate the proportion of the reserve requirement that remains to be satisfied together with expected changes in the autonomous liquidity factors. The Central Bank must also estimate how much of the supplied liquidity will remain "unused" for any of these purposes, and the error in that estimate will result in the market imbalance. What makes the exercise tricky is that, unlike the autonomous liquidity factors, the value of the excess reserves might indeed be correlated with the allotment. As an example, consider a policy in which the Central Bank forces front-loading behaviour by supplying excess liquidity early in the maintenance period and removing it toward the end. One consequence of such a policy is the increased number of banks that will satisfy the reserve requirement before the end of the maintenance period, thereby implying an increased probability of excess reserves. An increase in excess reserves works the same way as an increase in autonomous liquidity factors and has a negative effect on the available market liquidity thereby potentially diminishing the effectiveness of the liquidity supply. In practice, however, no such pattern is observed. Miscalculations of the excess reserve value add to the errors when estimating changes in autonomous liquidity factors and do not distort the aggregate deficiency in a significant manner.

\footnotetext{
${ }^{13}$ Excess reserves are the funds stored in the ECB account which are not reported to the deposit facility after satisfying all the reserve requirement. The underlying reason for the existence of those reserves are the costs associated with the standing facilities, which might discourage some banks from their use.
} 


\begin{tabular}{|c|c|c|c|}
\hline parameter & value & standard error & t-value \\
\hline \hline$\alpha$ & $-12.094,2$ & 12.680 & -0.954 \\
\hline$\beta$ & 0.1027 & 0.0103 & 9.98 \\
\hline$R^{2}$ & 0.54 & - & - \\
\hline
\end{tabular}

Table 3: Regression results

\subsection{Parameter calibration}

In order to simulate the behaviour of the whole market, I use the numerical methods presented in the following sections. I will show that the results are sensitive to the assumed variance of the liquidity shock as compared to the average current account balance. Using the individual bank data, I can actually try to estimate that relation for the Eurosystem and compare it to the assumptions made in existing literature.

In section 2.4, I discuss the relationship between shock volatility and bank size. To briefly summarise, large banks probably experience more late transaction requests or transaction errors simply due to the scale of their operations. They might employ additional staff to deal with those problems more efficiently, but it is unlikely that they are fully able to compensate for their size. This suggests that the liquidity shock and liquidity shock variance will be higher for larger banks.

Considering the available data, the first observation concerns extreme heterogeneity within the sample. Out of the 86 banks from which I collected data, the smallest bank average current account value was equal to EUR 230 thousand, while the largest one EUR 4.2 billion. The liquidity shock variance is likely to depend on several variables other than just the size of the bank. Bank type, country of origin and even ownership structure might determine the degree of randomness the bank is facing. Unfortunately, I do not have such detailed information, hence, the estimates presented here must be taken with caution.

Given the available information, I can approximate the parameters of the liquidity shock using a basic regression. The estimated equation takes the form:

$$
S E_{i}=\alpha+\beta a_{i}+\epsilon .
$$

$S E_{i}$ is the average standard deviation of liquidity shocks for bank $i$ measured across 15 realisations for the last days of the maintenance period. $a_{i}$ is a simple average current account value for bank $i$ and $\epsilon$ is the error term. The results of the regression are presented in the Table 3.

The parameter $\beta$, which is the key for my model, is statistically significant with a sufficient level of confidence to justify its use in the simulation stage. It seems that the volatility the banks are facing is indeed quite small when comparing the values assumed, for example, in Pérez-Quirós and Rodríguez-Mendizábal 
(2006) (their corresponding $\beta$ parameter was close to one). The discussion of the impact of the parameter value on the model behaviour is included in the section 5 , but the results of the paper are robust with respect to substantial deviations from this estimate.

In the simulation, I had to take into account grid limitations (I calculate the possible states for the grid size equal to 3 times the shock standard deviation) and assumed the shock with a standard deviation of $10 \%$ of the current account value. Recalculating the simulation with an even lower volatility does not change the results; using significantly higher values, however, moves the results toward those of other researchers. This only occurs at the shock standard deviation that is equal to roughly daily account value, which leaves me plenty of room for potential estimation errors.

\section{The simulation study description and discus- sion}

In this section, I apply the model discussed above to verify the behaviour of the interbank market given the estimated parameter values. The detailed description of the simulation method can be found in Appendix A.

\subsection{The shape of the demand schedule for risk neutral banks}

Before I move on to simulations, it is useful to once again come back to the demand schedule for an individual bank. Figure 1. presents the demand curves for the last 3 days of the maintenance period. To construct that figure, I arbitrarily assumed the current account balance and a daily reserve requirement equal to roughly 160 units. The liquidity shock has an assumed standard deviation of 50 units, which is much larger than my estimate but allows the pictures to remain clear.

Flat parts of the demand schedule, multiple borrowing values and the reserve requirement

First of all, note that for the days preceding the end of the maintenance period, there is a flat part of the demand schedule where different values of market liquidity result in the same interest rate. The size of the flat buffer is determined by the reserve requirement as documented in Figure 2, where I drew several demand curves with different value for the starting assets (corresponding to the reserve requirement). As the relative volatility increases, the flat part becomes shorter and shorter. 


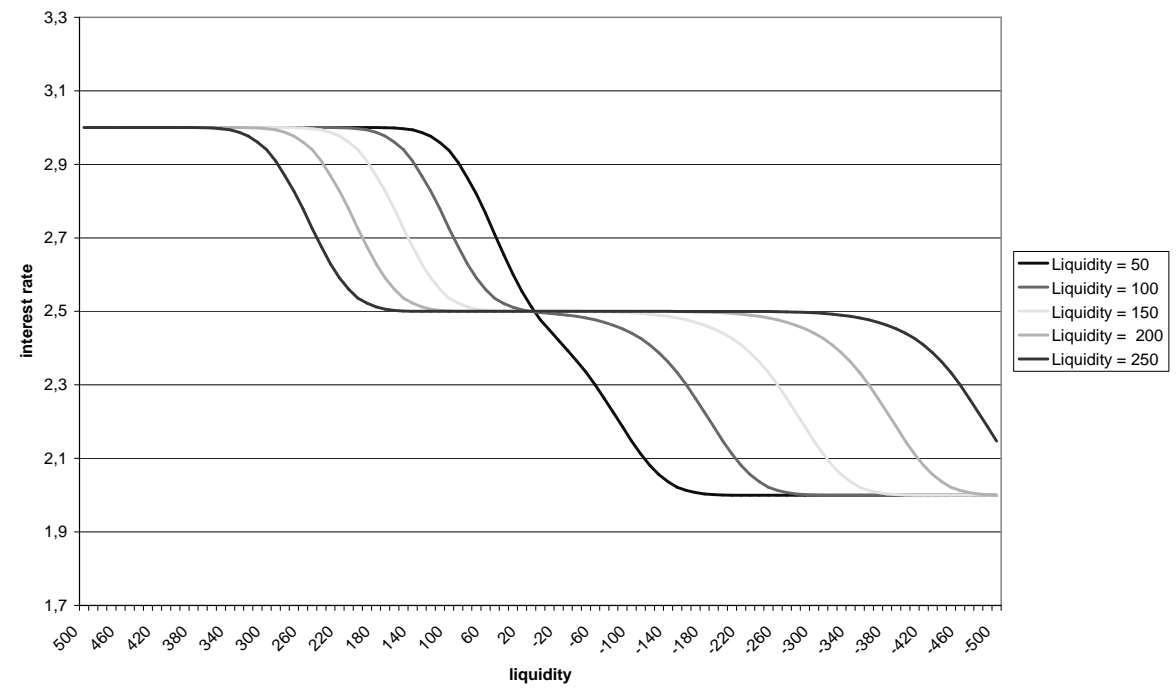

Figure 2: Different values of reserve requirement

It is perhaps easier to understand the relationship between the average current account value and the shock volatility by combining the graphical and algebraic interpretation. In order to draw Figure 2, I have assumed a normal distribution of the liquidity shock and have limited the grid of possible shocks to three times the standard deviation $\sigma .{ }^{14}$ This is a fairly mild assumption, widely used in the related literature, that covers $95 \%$ of the distribution and it is necessary to use numerical tools. With this assumption, however, I can solve equation (11) for three special cases.

Case 1 Large lending value $\left(b_{t}<-m_{t}-3 * \sigma\right)$

The condition $b_{t}<-m_{t}-3 * \sigma$ can be transformed into $-b_{t}-m_{t}>3 * \sigma$. Thus, assuming the shock realisation will never exceed three times its standard deviation, the expressions $F\left(-b_{t}-m_{t}\right) \rightarrow 1$ which implies also $F\left(d_{t}-b_{t}-m_{t}\right) \rightarrow$ 1. This means that the probability of a negative current account balance, at the

${ }^{14}$ The assumption is also used in the simulation study. 
end of the day, is one, and the bank will be forced to to use the Central Bank borrowing facility. Lending even more does not affect that probability (since it is already close to one), hence, the demand schedule is flat. Of course, the bank would only agree to lend so much at a market rate that no lower than the lending facility rate. In fact, using $F\left(-b_{t}-m_{t}\right)=1$ and $F\left(d_{t}-b_{t}-m_{t}\right)=1$ in equation (11) reduces it to:

$$
i_{t} \approx i^{l}
$$

Case 2 Large borrowing value $\left(b_{t}>d_{t}-m_{t}+3 * \sigma\right)$

For a sufficiently large borrowing value, $d_{t}-b_{t}-m_{t}<-3 * \sigma$, which implies $F\left(d_{t}-b_{t}-m_{t}\right) \rightarrow 0$ and $F\left(-b_{t}-m_{t}\right) \rightarrow 0$. The probability of the current account balance that exceeds all the remaining reserve requirement, at the end of the day, is one. Thus, by borrowing enough liquidity the bank is sure to satisfy its entire reserve requirement and the bank is forced to deposit any remaining reserves in the Central Bank. The bank would only borrow such reserves at the rate that is no higher than the deposit facility rate. Substituting $F\left(d_{t}-b_{t}-m_{t}\right)=0$ and $F\left(-b_{t}-m_{t}\right)=0$ in eq.(11) leads to:

$$
i_{t} \approx i^{d}
$$

Case 3 Intermediate borrowing value $\left(-m_{t}+3 * \sigma<b_{t}<d_{t}-m_{t}-3 * \sigma\right)$

At some intermediate borrowing value, within a specific range of values of $m_{t}, \sigma$, $d_{t}$ (so that there exists a $b_{t}$ that can satisfy this condition),

$$
-b_{t}-m_{t}<-3 * \sigma \quad \text { and } \quad d_{t}-b_{t}-m_{t}>3 * \sigma
$$

assuming normality means that the distribution functions of shock realisations converge to $F\left(-b_{t}-m_{t}\right) \rightarrow 0$ and $F\left(d_{t}-b_{t}-m_{t}\right) \rightarrow 1$. The last expression can be also presented as $1-F\left(d_{t}-b_{t}-m_{t}\right) \rightarrow 0$. Now both the probability of a negative current account balance and the probability of satisfying all the remaining reserve requirement, are zero. It can be shown that in order for such a borrowing value to exist, the deficiency must be significantly larger than the standard deviation of the shock. A simple transformation of eq. (29) yields:

$$
d_{t}>6 * \sigma
$$

Since $d_{t}$ is diminishing throughout the maintenance period, the condition is much more likely to hold in the earlier rather than in the later part of the maintenance period. Additionally, as the starting deficiency is linked with the current account value and the length of the maintenance period, the condition is also more likely to hold for markets with long maintenance periods and high values of reserve requirement (compared with the liquidity shock volatility).

Using $F\left(-b_{t}-m_{t}\right)=0$ and $F\left(d_{t}-b_{t}-m_{t}\right)=1$ in the equilibrium condition (11) results in:

$$
i_{t} \approx-\int_{-m_{t}-b_{t}}^{d_{t}-b_{t}-m_{t}} \frac{\partial V_{t+1}}{\partial d_{t+1}} f\left(\varepsilon_{t}\right) d \varepsilon_{t}
$$


so the interest rate is fully determined by the dynamic cost factor. For the analysed range of borrowing, this expression can be simplified as

$$
i_{t} \approx-\int \frac{\partial V_{t+1}}{\partial d_{t+1}} f\left(\varepsilon_{t}\right) d \varepsilon_{t}
$$

I can compute the derivatives of the value function $\frac{\partial V_{t}}{\partial d_{t}}$ using eq.(9) for the last day of the maintenance period:

$$
\frac{\partial V_{T}}{\partial d_{T}}=-i_{T}
$$

and using eq.(12) for the preceding days:

$$
\begin{aligned}
\frac{\partial V_{T-1}}{\partial d_{T-1}}=-i^{d}\left[1-F\left(d_{T-1}-\right.\right. & \left.\left.b_{T-1}-m_{T-1}\right)\right] \\
& +\int_{-\infty}^{d_{T-1}-b_{T-1}-m_{T-1}} \frac{\partial V_{T}}{\partial d_{T}} f\left(\varepsilon_{T-1}\right) d \varepsilon_{T-1}
\end{aligned}
$$

In order to further simplify this expression, I can use $F\left(d_{t}-b_{t}-m_{t}\right)=1$, and the above condition (33) to obtain:

$$
\frac{\partial V_{T-1}}{\partial d_{T-1}}=i_{T}
$$

Provided the reserve requirement buffer given by $\left(d_{t}-b_{t}-m_{t}\right)$ is sufficiently large, and the borrowing remains in a certain range, so that $F\left(d_{t}-b_{t}-m_{t}\right)=1$, the property (35) holds for all days $t$ preceding the end of the maintenance period. Recall that the derivative of the value function indicates how much an extra unit of deficiency changes the expected cost of borrowing and is referred in a literature as the dynamic cost factor. The interpretation of eq.(35) is that under certain assumptions, the dynamic cost factor remains constant, equal to the expected level of the interest rate for every day of the maintenance period.

This property combined with condition (32) can be presented as:

$$
i_{t}=E\left(i_{T}\right),
$$

which is an illustration of the celebrated martingale hypothesis. If the current interest rate is equal to the expected rate in the future, the optimal borrowing will be carried out within a range that will ensure that neither the deposit nor lending facilities are ever used. The range of possible borrowing decisions that could satisfy this condition is determined by the size of the remaining deficiency when compared to liquidity shock volatility. Early on in the maintenance period (when the deficiency is large), or for banks that face relatively little volatility, the range of possible borrowing decisions will be very large, thus the equilibrium interest rate equal to the expected level is very likely to clear 
the market.

In this case, however, the interbank rate is mostly determined by the expectations of the future interest rate, and is independent from the standing facilities rate or current liquidity. As the end of the maintenance period draws closer, the remaining deficiency becomes smaller compared to the shock volatility and it is the current liquidity and implied probabilities of using the standing facilities that determine the level of the interest rate.

This is a very important observation, as it might answer the question as to why the martingale hypothesis only holds true only for some interbank markets. In the markets with a significant reserve requirement (such as the Eurosystem) and long maintenance periods, it is probably going to last until the end of the maintenance period.

This observation was, in fact, confirmed in the empirical papers published in the ECB working series. Moschitz (2004) builds a model of Euro Overnight Index Average (Eonia) taking into account policy variables and operating policy (such as open market operations). He finds that the liquidity effect only holds for the four last days of the maintenance period, and that the main determinants of the interest rate for the rest of the maintenance period are the expected policy rate and expected liquidity on the last days of the maintenance period. Similar results are obtained by Würtz (2003), who reports that the liquidity only has an effect on the last two days of the maintenance period. The most significant determinant of the interest rate is the expected policy rate.

The fact that some part of the demand schedule has a flat component has implications for the determination of the market equilibrium within the framework of this model.

If the interest rate is equal to the expected level, the individual banks do not have a strictly determined optimal borrowing level. That means that there might be multiple market clearing equilibria, each of them at the same level of interest rate at different individual borrowing values. In fact, using Figure 1, an equilibrium where all banks chose the point close to $\mathrm{X} 1$ is possible. But that means that there will be an aggregate surplus of liquidity and the interest rate will remain at the expected level.

This has important policy applications as it explains the reaction of the whole market to aggregate liquidity changes. On one hand, the reserve requirement secures the market from unexpected aggregate shocks, such as a change in the autonomous factors which leads to a very low volatility of the interest rate. This pattern has been well documented in Moschitz (2004) and Würtz (2003), but another illustration is presented in Figure 3, which shows the spread before the ECB target rate and Eonia. The only spikes on otherwise flat graph happen at the end of the maintenance period.

From the Central Bank's perspective, such behaviour in the market indicates that the liquidity injections, which are the main tool of the monetary policy, will remain largely inefficient in controlling the market interest rate for the majority of maintenance period. In order to affect the level of the interest rate 


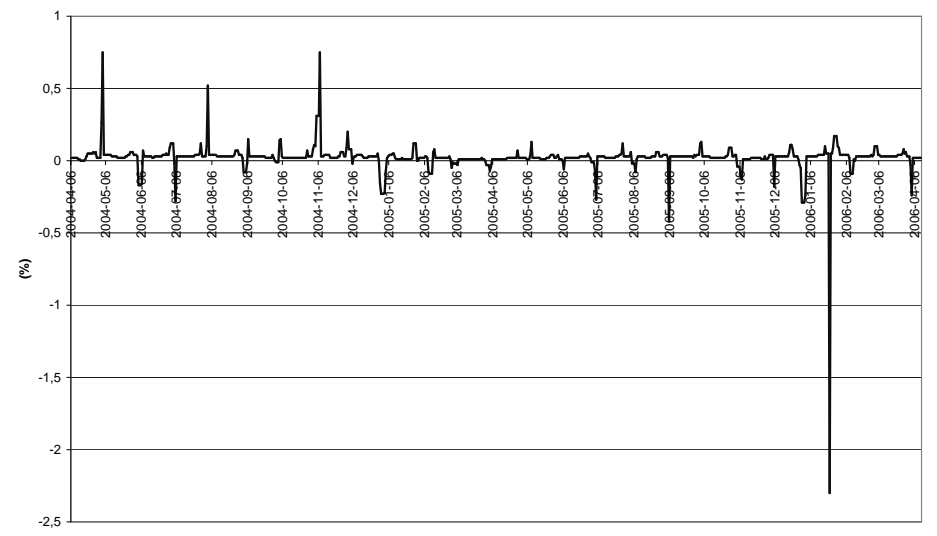

Figure 3: Euro Overnight Index Average (Eonia) Spread

for the interbank market, the central bank needs to focus on the control of the expectations.

This feature has also affected the design of the simulation. In particular, I was faced with the problem of which equilibrium point to choose, provided the interest rates remain on target. I have decided in favour of the liquidity neutral policy (that is, each bank attempts to end the day with the current account equal to average required reserves) but the framework of this paper is not sufficient to theoretically justify that choice. However, if banks wanted to avoid excess borrowing and lending, intuitively the best strategy would involve setting the current account volume to the average required level.

To summarise the findings of this section, the shape of the demand schedule might have significant policy implications. Provided that the expectations for future interest rates remain unchanged, the market will not react to small changes in liquidity, resulting, for example from errors in the estimations of the autonomous liquidity factors. 


\section{The demand schedule under a liquidity shortage}

The inspection of the demand schedule (for example in Figure 1) reveals that it takes a very similar shape under a liquidity shortage (left part of the graph) for the days preceding the end of the maintenance period. On the other hand, the demand seems to differ for different days under the liquidity excess. This is related to a certain asymmetry in the averaging provision reserve requirement regime. In eq. (11) the probability of using the lending facilities (under liquidity shortage) depends solely on the current account balance which remains relatively stable for different days of the RMP. Thus, for all the days, the probability of using the lending facility remains essentially the same. However, the probability of using the deposit facility is tied to the remaining deficiency value, which decreases toward the end of the maintenance period (recall the condition (30)). This means the demand schedule at excess liquidity will have different shape for different days of the maintenance period.

This particular feature might be important in an analysis of the behaviour of the interbank market when faced with an aggregate shock that is not offset by the Central Bank. In particular, the market behaviour might experience an asymmetric pattern depending on the direction of the shock. The prediction based on the model is that the interest rate is much more likely to deviate from the neutral level when the market is faced with a liquidity shortage, rather than a liquidity surplus.

\subsection{Central Bank intervention}

The demand curves in the section above were constructed under constant interest rate expectations. In reality, however, this might constitute a very strong assumption. The section below justifies using it in the simulation model.

The most important reasons for the rate to deviate from the target on the last day of the maintenance period are:

1. Due to the fact that banks want to avoid the "lock-in" state (when all the deficiency is exhausted) the model predicts some incentives for backloading (postponing satisfying the reserve requirement until the end of the maintenance period), which would lower the average rate in the beginning of the period and raise it at the end. These incentives are particularly strong for a case where the reserve requirement buffer is low compared to the shock volatility.

2. During the maintenance period, some banks make errors in the liquidity management that force them to use their standing facilities. This results in an aggregate change in the market liquidity, which is then directly reflected on the last day. Sophisticated banks will base their expectations on the estimated level of liquidity at the end of the maintenance period.

3. Variable rate tenders tend to typically end up with a marginal allotment rate (all bids above that rate are accepted) that is higher than the min- 
imum bid rate (set at the target level). If the banks believe that the marginal allotment rate is a better proxy for future market rates, they will adjust their expectations accordingly. ${ }^{15}$

These points illustrate the fact that there are solid reasons why the expectations might differ from the target level of the Central Bank. In order to counter these effects, the ECB performs several interventions during the maintenance period including fine tuning operations on the very last day of the maintenance period.

Operations implemented at the end of the maintenance period, if performed in a timely and precise fashion, can, in practice, cancel out the first two effects listed above, but may face some troubles in countering the last one. This is caused by the design of open market operations, and, in particular, their asymmetric nature in the ECB regime. Depending on whether they constitute liquidity supply or draining, they take the form of either variable or fixed rate tenders. In variable rate tenders, the rate at which funds are supplied is typically higher than the minimum bid rate, which has been discussed in detail by Välimäki (2006). Liquidity draining operations are performed in the form of fixed rate tenders that efficiently anchor the rate at the target level. That means, however, that the policy will only be able to efficiently tie the market interest rate to the desired level in a case where there is a liquidity surplus, and will fail to do that under a liquidity shortage. Since the ECB can chose whether to enter the last part of the maintenance period with an aggregate liquidity shortage or surplus (by adjusting the previous operation volumes), it can effectively control the level of the interest on the last day of the maintenance period and the corresponding expected levels.

This policy is reflected in the simulation code. In practice, I assume that the Central Bank adjusts the aggregate market liquidity to neutral level on the last day of the maintenance period. ${ }^{16}$

\subsection{Risk aversion}

Before moving to the actual simulation study, let me elaborate on the issue of risk aversion.

In the model above I have assumed risk neutrality which implied the banks only care for the expected cost of funding. In reality however, one might question such an assumption and argue instead that banks are risk averse. That means that the banks not only care about the expected value of their funding cost but also about the cost variance.

In particular, one might suspect that since the last day typically experiences the highest variance of the interest rate, banks that expect a net outflow of liquidity would like, for example, to front-load in order to avoid using the market as a funding source.

\footnotetext{
${ }^{15}$ In fact, some indication of such a behaviour has been found in Würtz (2003).

${ }^{16}$ By neutral level, I mean the central account balances that are equal to the remaining part of the reserve requirement.
} 
To see how a bank might accomplish that within this framework, one can use the model to compute the last day profit variance. For the last day of the maintenance period, the cost equation (3) implies ${ }^{17}$ :

$$
\operatorname{var}(\operatorname{cost})=\operatorname{var}\left(i_{T} b_{T}+E\left(c_{T}\right)\right)=\operatorname{var}\left(i_{T} b_{T}+\left(i^{l}-i^{d}\right)\left[\int_{0}^{\infty} \varepsilon_{T} f\left(\varepsilon_{T}\right) d \varepsilon_{T}\right]\right)
$$

The second part of the expression in brackets is just an expected value of cost which - at optimal borrowing - is always equal to zero. That allows for a further simplification of eq. (37):

$$
\operatorname{var}\left(i_{T} b_{T}\right)=b_{T}^{2} \operatorname{var}\left(i_{T}\right)=\left(d_{T}-m_{T}\right)^{2} \operatorname{var}\left(i_{T}\right) .
$$

The variance of the cost depends on the interest rate variance and the value of interbank trade ${ }^{18}$.

What can a risk averse bank do to minimise its risk exposure? I can safely assume that the variance of the interest rate is exogenous, and the starting value of current account $m_{T}$ on day $T$ is determined by past shock realisations. The only variable that can be controlled by the bank is the deficiency $d_{T}$ given by

$$
d_{T}=d_{T-1}-m_{T-1}-\varepsilon_{T-1}-b_{T-1} .
$$

A bank that is willing to minimise the variance in the last period needs to adjust his borrowing activity so that

$$
E\left(d_{T}\right)=E\left(m_{T}\right) .
$$

This condition will be satisfied at a borrowing value of

$$
b_{T-1}=d_{T-1}-2 * m_{T-1},
$$

which means that the risk aversion motive might determine the exact value of borrowing for all days preceding the end of the maintenance period.

\section{Simulation results}

The above sections contain the analytical analysis of the base model. The crucial equations become, however, analytically intractable for more than 3 periods while in reality, the maintenance periods stretch as far as 20 days (in

\footnotetext{
${ }^{17}$ As shown in Appendix E.

${ }^{18}$ To understand the last transition, recall from the previous sections that on last day of the maintenance period, the optimal borrowing is the simple difference between the bank's assets and remaining deficiency.
} 
the Eurosystem). Hence, to analyse the behaviour of the model in a more realistic scenario, I turn to numerical simulations.

The first scenario that I look into is the benchmark model where I assume homogeneous banks, a symmetric corridor system, aggregate liquidity sufficient to satisfy the reserve requirement and a low value for the liquidity shock variance, which resembles the Eurosystem. In later sections, I allow for heterogeneity, an asymmetric corridor system, aggregate shock and different values for the idiosyncratic shock variance to see the impact of those assumptions on the market behaviour. A summary concludes this section.

The results of the simulations are presented in the form of tables. Each table includes the following information:

- the average market clearing rate for each day of the maintenance period (the Central Bank target is 2.5\%),

- the interest rate volatility,

- the average use of the standing facilities.

\subsection{Benchmark scenario}

I start out by presenting the results for a benchmark scenario with the following assumptions:

1. The banks are homogeneous; each of them has the same asset and deficiency value as well as being faced by i.i.d. liquidity shock (for heterogeneity, see section 6.2.).

2. The liquidity shock is idiosyncratic in that there is no aggregate shock to the market (as it is fully offset by the Central Bank). For the analysis of the aggregate shock, see section 6.4.

3. The parameters of the simulation are calibrated to the Eurosystem values. The most important parameter is the shock volatility as compared to the bank's assets. Based on the discussion in the section above, I have used a shock standard deviation equal to roughly $1 / 10$ of the bank asset size. For a different size of the shock variance, check section 6.5 .

4. With no aggregate liquidity outflow (or inflow), there is no practical need for extra Central Bank intervention on the last day of the RMP apart from a countering of the use of the standing facilities during the maintenance period.

5. A symmetric corridor system with the target rate that lies between the standing facilities rate. For an asymmetric corridor, see section 6.3.

The parameters of this scenario were chosen to resemble the Eurosystem. The reserve requirement is very high, which forces the commercial banks to maintain

a high value for the current account (in the simulation, I use an assets size of 


\begin{tabular}{|c|c|c|c|c|}
\hline Day & Mean Rate & Rate Volatility & Deposit facility & Lending facility \\
\hline \hline 1 & 2.50 & - & - & - \\
\hline 2 & 2.50 & - & - & - \\
\hline$\ldots$ & 2.50 & - & - & - \\
\hline 19 & 2.50 & - & - & - \\
\hline 20 & 2.50 & 0.00 & 43.00 & 43.00 \\
\hline
\end{tabular}

Table 4: The benchmark scenario

The mean and standard deviation (volatility) of the interest rate; deposit/lending facility values refer to the average use across all simulation runs.

100, where the liquidity shock standard deviation is 10). That, however, means that the shocks are not likely to force the commercial bank to use the standing facilities during the maintenance period. That is, indeed, what I observed in the simulation results presented in Table 4, where the differences in the target interest rate level drop to zero for all days of the maintenance period. With the shock so small, hardly any bank risks making mistakes and losing their reserve requirement buffer too soon; this means that, on the last day of the RMP, the market liquidity will be just sufficient to satisfy the reserve requirement hence no last day operations are necessary (or their volume is zero). This, according to equation (5), means that the rates remain exactly on target.

Despite having no volatility at all, the scenario can be used to gain some interesting insight. Probably the most important factor one concerns the importance of the idiosyncratic shock on the behaviour of the interbank market. Pérez-Quirós and Rodríguez-Mendizábal (2006) explain the deviation from the martingale hypothesis with simply an idiosyncratic shock that stimulates backloading ${ }^{19}$ to avoid a lock-in state (where the deficiency is satisfied before the end of the maintenance period). Here, I find that in case of the values of the liquidity shock variance that are close to those of the Eurosystem, this effect while still possibly present - is too small to make any difference. This is related to the modelling strategy and the flat shape of the demand curves (see section 5.1 for details), which results in market clearing rate equal to the expected rate for a wide range of borrowing decisions. Thus, the individual realisation of the idiosyncratic shock and distribution of liquidity among the banks seem to play no significant role in the evolution of the interest rate.

In the remaining part of the section, I will attempt to verify the robustness of those results by analyzing some of the assumptions utilised.

\subsection{Heterogeneous banks}

In the benchmark scenario from section 6.1, I have assumed that all the banks are homogeneous and are facing shocks drawn from the same distribution. With

${ }^{19}$ Postponing satisfaction of the reserve requirement. 
the reserve requirement (or average current account volume) at a fairly high level in comparison with the volatility of the liquidity shock, the probability of being forced to use the standing facilities was very low. That meant that there was nearly always an equilibrium where the market cleared at the target rate (equal to the expectations for the last day's rate).

In this section, I attempt to verify if the results still hold when I allow for:

- Heterogeneous banks - more specifically, I use two groups of banks with different assets.

- Heterogeneous exposure to the liquidity shock - by forcing both small and large banks to draw their shocks from the same distribution.

This might be justified in the following way. In reality, the market experiences much more variety. There are both large and small banks subject to the reserve requirement and liquidity shock, as indicated in my sample. Recall that the average current account size was EUR $760 \mathrm{M}$ with a standard deviation EUR $960 \mathrm{M}$. It might then be useful to analyse the importance of the homogeneity assumption, and I have repeated the simulations for a heterogeneous case. First, I divided the banks into 2 groups. One group was given an assets size of 100 (as in the benchmark case) and the other of 10 (equal to the shock standard deviation).

In the benchmark scenario, I have assumed that the bank size and liquidity shock variance is proportional. The regression from section 4 confirms that such a link indeed exists, but also that there is a lot left unexplained by simply looking at the current account size, and small banks might be, in fact, subject to larger shocks (relative to their size) than big banks. Therefore, it might be interesting to verify how important the homogeneity assumption is for my results.

For that, I subject both bank groups to the liquidity shock drawn from the same distribution. That means that nothing changes for large banks compared to benchmark scenario, but small banks now face a substantial increase in uncertainty.

The results from the simulation are presented in Table 5. As one could predict, the smaller banks are much more likely to use their standing facilities, especially the lending facility. The reason is that, with such a small reserve requirement, their average current account balance is way too small to sufficiently protect them against late negative shocks. After several periods, some of them also lose the reserve requirement buffer and (starting from period $t=11$ ) they start using the deposit facility as well. Those in a lock-in state have no more incentives to maintain a positive balance on the current account (as the relative expected cost of lost profits is equal to the expected cost of the borrowing facility), thereby reducing their balances to zero and further increasing the frequency of the need to use the lending facility. These observations only concern small banks. Those banks with a large buffer are not affected by the use of the 


\begin{tabular}{|c|c|c|c|c|}
\hline Day & Mean Rate & Rate Volatility & Deposit facility & Lending facility \\
\hline \hline 1 & 2.50 & - & - & 5.34 \\
\hline 2 & 2.50 & - & - & 5.56 \\
\hline 3 & 2.50 & - & - & 6.14 \\
\hline 4 & 2.50 & - & - & 5.63 \\
\hline 5 & 2.50 & - & - & 6.06 \\
\hline 6 & 2.50 & - & - & 6.42 \\
\hline 7 & 2.50 & - & - & 6.52 \\
\hline 8 & 2.50 & - & - & 6.41 \\
\hline 9 & 2.50 & - & - & 6.22 \\
\hline 10 & 2.50 & - & - & 4.49 \\
\hline 11 & 2.50 & - & 0.00 & 3.62 \\
\hline 12 & 2.50 & - & 0.02 & 3.69 \\
\hline 13 & 2.50 & - & 0.08 & 5.09 \\
\hline 14 & 2.50 & - & 0.53 & 11.30 \\
\hline 15 & 2.5001 & 0.0002 & 15.31 & 33.53 \\
\hline 16 & 2.5001 & 0.0003 & 16.81 & 32.02 \\
\hline 17 & 2.5002 & 0.0004 & 14.71 & 26.93 \\
\hline 18 & 2.5002 & 0.0004 & 14.21 & 22.63 \\
\hline 19 & 2.4996 & 0.0067 & 14.55 & 20.08 \\
\hline 20 & 2.50 & 0.0000 & 43.30 & 43.30 \\
\hline
\end{tabular}

Table 5: Heterogeneous banks

The mean and standard deviation (volatility) of the interest rate; deposit/lending facility values refer to the average use across all simulation runs. 
standing facilities until the last day of the maintenance period, when the aggregate liquidity shortage (or excess) is transmitted to the behaviour of the interest rate. In this scenario, however, I do allow for the Central Bank intervention, which assures that the interest rate level on the last day of the RMP stays on target (hence, no volatility on the last day).

The impact of heterogeneity on the interest rate is very small. For the better part of the maintenance period, even though there is a constant inflow of liquidity (from the borrowing facility used by small banks), it is still possible to find borrowing levels that would clear the market at the target rate. This only changes later on in the maintenance period, resulting in a tiny volatility of the interest rate, which at most reaches a value of 0.007 . This is due to the fact that small banks have very little effect on the market behaviour as a whole.

The conclusion for this section is that the introduction of heterogeneity does have an impact on the use of the standing facilities, but it is too small to substantially affect the market rate.

\subsection{Asymmetric corridor system}

In the simulation design this so far, I have assumed that the expected (and the Central Bank target) rate lies exactly between the deposit and lending facility rate. The implications of this assumption are discussed in this section.

The spread between the standing facility rates offered by the ECB is fixed at 200 basis points and the target rate falls precisely in the middle of the corridor. The symmetry of the corridor is, however, distorted by additional factors that restrict the use of the facilities. This can be confirmed by analysing the available data on the spread between the Eonia and ECB target and the liquidity conditions on the last day of the maintenance period. It can be shown that even though the model predicts that for the symmetric corridor, the neutral liquidity in the last day of the maintenance period should result in a rate exactly in the middle of the target, this is not actually the case. A simple regression of the spread on the net use of the standing facilities has a constant component equal to roughly 7 basis points. Also, the analysis of the use of the facilities reveals that the deposit facility is much more often used than the lending facility, which, according to the Poole model, should create an easy arbitrage opportunity without additional costs.

One explanation for this puzzle might be related to the collateral required to use the lending facilities. Also, the banks need to apply to use the facility each time, thereby creating some operating expenses. ${ }^{20}$ Since the penalties for overdraft far exceed the cost of lost profits from the deposit facility, banks that want to play it safe will prefer to maintain a surplus rather than risking a shortage. Finally, there might be several other factors which are not so easy to

\footnotetext{
${ }^{20}$ Although some countries in the Eurosystem, such as Finland, allow for the automatic use of the standing facilities.
} 
quantify that could distort the symmetry of standing facilities. An example of this would be window dressing at the end of the year.

Those restrictions introduce a certain asymmetry into the actual cost of the standing facilities as perceived by the commercial banks, and, in this section, I analyse the impact of this asymmetry on the model behaviour. In particular, I analyse a case where the cost of the lending facility is higher than the nominal value.

The actual modification of the model, in order for it to reflect asymmetric facilities, is fairly straightforward. Since the incentives I mentioned above are present in all the days of the maintenance period, I increase the lending facility rate by 20 basis points throughout the entire simulation. A brief inspection of the condition (5) for the last day of the maintenance period reveals that raising the lending rate $i^{l}$ means that the equilibrium interest rate at neutral liquidity (when the use of both standing facilities is equally likely) will be above the central target. But that means that without an additional Central Bank intervention, the expected rate on the last day will raise with a corresponding increase in the rate for an every day of the maintenance period. The results from the simulation (not reported here since they closely resemble the benchmark scenario) confirm that such behaviour actually takes place.

\subsection{Aggregate shock}

In the scenarios described above, I have assumed that the liquidity shock is idiosyncratic and have found that its impact on the interbank market (for the parameter values close to the Eurosystem) is small. If the Central Bank's interventions to offset the changes in the autonomous liquidity factors are performed frequently, the only outflow (or inflow) of liquidity could result from the use of the standing facilities. In this section, I modify that assumption and allow the aggregate liquidity to change every day.

In terms of modelling, this can be accomplished by adding an additional early shock realisation to the model. The timing looks almost identical to the one presented before:

$$
\begin{array}{lllll}
m_{t}, d_{t} & \varepsilon_{e t} & b_{t} & \varepsilon_{t} & m_{t+1}, d_{t+1}
\end{array} .
$$

The additional shock $\varepsilon_{e t}$ occurs in the morning, before the market opens and $b_{t}$ is calculated. I assumed this shock to have parameters similar to the idiosyncratic one (i.e. the mean zero and standard deviation $\sigma=10$ ), but its aggregate value might be different from zero. In order to assure that the market expectations of the interest rate are correct, I need the central bank intervention on the last day of the maintenance period.

The results are presented in Table 6 . Note that the use of the lending facility does not change from the benchmark scenario. This is obvious: unless the 


\begin{tabular}{|c|c|c|c|c|}
\hline Day & Mean Rate & Rate Volatility & Deposit facility & Lending facility \\
\hline \hline 1 & 2.50 & - & - & - \\
\hline 2 & 2.50 & - & - & - \\
\hline$\ldots$ & 2.50 & - & - & - \\
\hline 12 & 2.50 & - & - & - \\
\hline 13 & 2.50 & 0.00 & - & - \\
\hline 14 & 2.50 & 0.00 & - & - \\
\hline 15 & 2.50 & 0.00 & - & - \\
\hline 16 & 2.50 & 0.02 & 0.42 & - \\
\hline 17 & 2.49 & 0.07 & 8.95 & 0.01 \\
\hline 18 & 2.44 & 0.16 & 64.42 & 0.20 \\
\hline 19 & 2.35 & 0.22 & 216.72 & 47.88 \\
\hline 20 & 2.51 & 0.14 & 47.96 & \\
\hline
\end{tabular}

Table 6: Aggregate shock

The mean and standard deviation (volatility) of the interest rate; deposit/lending facilities values refer to the average use across all simulation runs.

banks lose their reserve requirement bonus, they will be inclined to maintain the current account balance sufficient to offset a negative liquidity shock. Recall that the late liquidity shock has a small variance compared to the asset value.

I will analyse the cases of aggregate liquidity shortage and surplus separately as they occur with the same probability, but have quite a different impact on the market behaviour.

First, assume that the additional shock caused an aggregate liquidity shortage on the market. The banks' current account balances are lower, but, with a low shock volatility, even the remaining balances are sufficient to protect them from the borrowing facility. The satisfaction of the reserve requirement is behind schedule (in comparison to the benchmark), but the banks assume that by the last day of the maintenance period the Central Bank will provide the liquidity necessary to satisfy the reserve requirement. That causes the temporary shortage of liquidity to have little impact on the use of the standing facilities and interest rate.

On the other hand, the scenario involving a liquidity surplus is more interesting. Even a minor liquidity surplus from, for example, day $t=1$ that is not countered by the Central Bank intervention (which is assumed to happen only on the last day) contributes to the reserve requirement for each day of the remaining part of the maintenance period. This might cause some banks to end up in the lock-in state and explains the use of the deposit facilities.

The behaviour of the interest rate can be explained by a combination of those two effects. In this scenario, the market is either short or has a surplus of liquidity. The market is not affected by the liquidity shortage, but the surplus will cause some banks to become locked up, thereby forcing them to use the 
deposit facility and depressing the interest rate.

This section offers some interesting findings in terms of the optimal policy setup. The results suggest that in order to keep the interest rate equal to the target level in the presence of aggregate shocks, it is actually better to maintain an aggregate liquidity shortage for the entire maintenance period and to supply the amount required to satisfy the reserve requirement on the last day. This would allow the banks to sustain the reserve requirement buffer while maintaining sufficient funds to offset negative late shocks. A reverse policy (i.e. liquidity surplus during the maintenance period and a draining of the excess on the last day) could result in several banks finding themselves in a lock-in state, which drives the rate below the target as they have no way to insure against positive shocks.

\subsection{Large idiosyncratic shock}

In the scenarios presented above, I have demonstrated that an idiosyncratic shock of a size similar to the one observed in the Eurosystem has little impact on the behaviour of the interest rate. In this section, I analyse what happens if the liquidity shock volatility is higher and the model is otherwise unchanged.

In terms of modelling assumptions, I set the variance of the liquidity shock at $\sigma=100$ (compared with $\sigma=10$ in the benchmark scenario), which is equal to the starting assets value. Similar parameter values were used in earlier research. I have assumed that the Central Bank intervention provides the market with neutral liquidity on the last day of the maintenance period, thus also setting the expected interest rate at the target level. The results are presented in Table 7 .

Note that the increase in the standard deviation has a substantial impact on the market behaviour. The lending facility is used much more extensively, which can be explained by a much higher volatility of the shock compared to the average current account balance. Contrary to the benchmark case, this buffer does not seem to be too small to save the banks from the negative shocks. Increased volatility has, however, much less impact on the use of the deposit facility. This is due to the fact that the reserve requirement buffer (for 20 periods) is sufficient to secure the banks from even very large positive shocks. This explains the discrepancy in using the standing facilities observed in the simulation.

The constant use of the lending facility, without a corresponding increase in the deposit facility constitutes a steady inflow of liquidity in the system which, at some point, will drive the rates down. The banks still have the incentive for back-loading (as in the Pérez-Quirós and Rodríguez-Mendizábal (2006) model), which is reflected by a starting that is lower than the Central Bank target level. The back-loading is, however, smaller than the liquidity effect so the interest rate is decreasing. This was not observed by Pérez-Quirós and Rodríguez-Mendizábal (2006), as their model only covered 4 periods. 


\begin{tabular}{|c|c|c|c|c|}
\hline Day & Mean Rate & Rate Volatility & Deposit facility & Lending facility \\
\hline \hline 1 & 2.47 & - & - & 71.09 \\
\hline 2 & 2.47 & - & - & 67.08 \\
\hline 3 & 2.47 & - & - & 69.12 \\
\hline 4 & 2.47 & 0.00 & - & 72.11 \\
\hline 5 & 2.47 & 0.00 & - & 73.32 \\
\hline 6 & 2.47 & 0.00 & - & 75.91 \\
\hline 7 & 2.47 & 0.00 & - & 76.51 \\
\hline 8 & 2.46 & 0.01 & - & 77.01 \\
\hline 9 & 2.46 & 0.01 & - & 76.38 \\
\hline 10 & 2.46 & 0.01 & - & 76.89 \\
\hline 11 & 2.45 & 0.01 & 0.00 & 79.10 \\
\hline 12 & 2.45 & 0.01 & 0.00 & 80.36 \\
\hline 13 & 2.45 & 0.01 & 0.15 & 86.60 \\
\hline 14 & 2.44 & 0.01 & 0.75 & 91.04 \\
\hline 15 & 2.43 & 0.01 & 3.05 & 95.13 \\
\hline 16 & 2.42 & 0.02 & 13.08 & 101.23 \\
\hline 17 & 2.40 & 0.02 & 50.25 & 104.25 \\
\hline 18 & 2.35 & 0.04 & 183.24 & 110.94 \\
\hline 19 & 2.23 & 0.08 & 535.87 & 380.88 \\
\hline 20 & 2.50 & - & 380.88 & \\
\hline
\end{tabular}

Table 7: Large idiosyncratic shock

The mean and standard deviation (volatility) of the interest rate; deposit/lending facilities values refer to the average use across all simulation runs. 


\subsection{Simulation summary}

In the section above, I have presented the results of the simulations using the parameters calibrated in section 4 . I have also verified whether changing different assumptions will change the results in a significant way.

The main conclusion is that the benchmark model provides a good approximation of the actual market behaviour. In all days of the maintenance period, other than the last one the interest rate remains equal to the expected level. I observe little variation in the interest level, and hardly any bank satisfies the reserve requirement early. Since some of the underlying assumptions could be perceived as strong, I have also run the simulation by allowing banks to exhibit heterogeneity, an asymmetric corridor, aggregate shock and a large shock volatility.

The first scenario allows for the heterogeneity of the banks. Small banks are much more vulnerable to randomness and have to use the standing facilities more extensively. However, their influence is too small to significantly affect the whole market.

In the second scenario, I allow for an asymmetric corridor between the standing facilities. I find that the interest rate remains tied to the expected level on the last day of the maintenance period and that market behaviour depends on Central Bank's ability to affect those expectations.

In the third scenario, I allow for an additional early shock that affects the aggregate market liquidity. Perhaps the most interesting finding is that there is now an asymmetry between the use of the deposit and lending facilities. The average use of the lending facility is not affected, since the banks still have enough liquidity to secure safe end of the day balances (a shortage of liquidity is assumed to be covered by the Central Bank on the last day). If the market is, however, flooded with cash, more and more banks would find themselves in an irreversible lock-in state. In this case, the market rate would be pushed below the target. However, those results assume that the only Central Bank intervention takes place on the last day of the maintenance period.

Finally, I attempt to compare my model with the model of Pérez-Quirós and Rodríguez-Mendizábal (2006) by verifying what happens if I increase the liquidity shock variance. My model covers 20 periods (whereas they only look at a 4-day maintenance period) and the effect of the liquidity inflow from the lending facility exceeds the motivation to back-load, which is why I actually observe a drop rather than an increase in the interest rate. The rate, however, starts at a level below the target, which is consistent with their finding.

\section{Conclusions}

To summarise, the main finding of this paper is that the behaviour of the interbank interest rate is related to the relative size of the liquidity shock volatility and reserve requirement. I find that, for the Eurosystem, the volatility of the 
liquidity shock is significantly lower that the average current account holding. That has a significant impact on the behaviour of the interest rate throughout the maintenance period. Early on, the interest rate is determined by the expectations, and the market liquidity starts to matter only at the end of the maintenance period.

The most important theoretical contribution was to find and explain the flat parts in the demand schedule of individual banks.

If the market rates equal to standing facilities, the banks will be indifferent between the market borrowing and using the facilities.

At a market rate equal to the expected rate in the future, provided the deficiency is substantially larger than the shock volatility, the banks are indifferent between different levels of borrowing. This can be used to explain a low volatility and the lack of a liquidity effect in the market early on in the maintenance period.

In this paper, I also calibrated the size of the liquidity shock standard deviation relative to the average current account holdings, which seems to be a crucial relationship for the behaviour of the model. Based on the sample from 86 banks in the Eurosystem, I have found that the average shock standard deviation stands roughly at $10 \%$ of the current account on the last days of the maintenance period. Note that this is the first estimate of the liquidity shock size, hence, it is impossible to compare it directly with similar research in that field.

In the numerical part, I simulate the behaviour of the market for 20 periods. I found that, for the calibrated parameters, I was able to duplicate the behaviour of the Eurosystem fairly well. The market rate remains on target and the use of the standing facilities is very low. The robustness of the assumptions has been verified by running the simulations with bank heterogeneity, an asymmetric corridor system, aggregate shock and a large idiosyncratic shock. For each of these factors, I was able to explain the difference in comparison with the benchmark model.

\section{A Simulation description}

The problem has a recursive structure and, therefore, I start solving it from the last day of the maintenance period. The general algorithm takes the following form:

1. Calculate the possible states that include value functions for all the periods and possible assets paths

- To calculate the values of the assets, I use the grid equal to $3 \mathrm{x}$ the shock standard deviation (per one period) which covers most of the 
distribution. The deficiency can simply vary between $D$ (the amount set by the Central Bank) and zero.

- In period $T$, the value function is simply equal to the expected rate. Through most of the simulation, I assume that the expected rate is equal to the target of the Central Bank.

- In period $T-1$ and earlier, formula (12) is used to calculate the derivatives for each possible realisation of the assets and deficiency. The result $\frac{\partial b_{t}}{\partial m_{t}}=-1$, as shown in Appendix F, greatly simplifies the computations here.

2. Generate the idiosyncratic shock realisations and update the value of the assets for each bank separately.

3. Determine the market clearing rate and optimal borrowing

- To determine the interest rate, I am using a simple bijection algorithm: calculate the aggregate borrowing for 2 different rates and check, if for any of them, it is equal to zero. If so, I have found the market clearing rate; otherwise I repeat for the calculations for another guess of the interest rate.

- To find the value of aggregate borrowing, I have to calculate the borrowing of each individual bank separately. To do that, I utilise the formula (11) and use previously saved (in step 1) values of the derivative of the value function.

- Due to the fact that the demand curve has a flat component (especially at lower values of shock standard deviation in comparison to the assets and deficiency, such as is usually the case in the beginning of the maintenance period), it is possible that the same level of rates will correspond to different borrowing decisions. That leads to multiple equilibrium at the same interest rate, from which I pick the one that clears the market and is close to a neutral borrowing level.

4. Apply the borrowing decision as well as a final shock and calculate new states. Move one period ahead and repeat the procedure.

\section{B Proof of the results from section (3.1)}

The expected cost function can be then rewritten as

$$
i_{T} b_{T}+E\left(c_{T}\right)
$$


where $i_{T} b_{T}$ stands for the cost of interbank borrowing and $E\left(c_{T}\right)$ denotes expected the cost of using the standing facilities given by

$$
\begin{gathered}
E\left(c_{T}\right)=i^{l}\left[\int_{-\infty}^{-m_{T}-b_{T}+d_{T}}\left(-m_{T}-b_{T}+d_{T}-\varepsilon_{T}\right) f\left(\varepsilon_{T}\right) d \varepsilon_{T}\right] \\
-i^{d}\left[\int_{-m_{T}-b_{T}+d_{T}}^{\infty}\left(m_{T}+b_{T}-d_{T}+\varepsilon_{T}\right) f\left(\varepsilon_{T}\right) d \varepsilon_{T}\right]= \\
=-i^{l}\left(m_{T}+b_{T}-d_{T}\right) F\left(-m_{T}-b_{T}+d_{T}\right) \\
-i^{d}\left(m_{T}+b_{T}-d_{T}\right)\left(1-F\left(-m_{T}-b_{T}+d_{T}\right)\right) \\
-i^{l} \int_{-\infty}^{-m_{T}-b_{T}+d_{T}} \varepsilon_{T} f\left(\varepsilon_{T}\right) d \varepsilon_{T}-i^{d} \int_{-m_{T}-b_{T}+d_{T}}^{\infty} \varepsilon_{T} f\left(\varepsilon_{T}\right) d \varepsilon_{T}
\end{gathered}
$$

The first order conditions for that problem with respect to $b_{t}$ are:

$$
\begin{gathered}
-i_{t}=-i^{l} F\left(-m_{t}-b_{t}+d_{t}\right)+i^{l}\left(m_{t}+b_{t}-d_{t}\right) f\left(-m_{t}-b_{t}+d_{t}\right) \\
\quad-i^{d}\left(1-F\left(-m_{t}-b_{t}+d_{t}\right)\right)-i^{d}\left(m_{t}+b_{t}-d_{t}\right) f\left(-m_{t}-b_{t}+d_{t}\right) \\
-i^{l}\left(m_{t}+b_{t}-d_{t}\right) f\left(-m_{t}-b_{t}+d_{t}\right)+i^{d}\left(m_{t}+b_{t}-d_{t}\right) f\left(-m_{t}-b_{t}+d_{t}\right)
\end{gathered}
$$

where the last line follows from the Leibniz rule. Rearranging yields:

$$
i_{t}=i^{l} F\left(-m_{t}-b_{t}+d_{t}\right)+i^{d}\left(1-F\left(-m_{t}-b_{t}+d_{t}\right)\right)
$$

\section{Proof of the results from section (3.2)}

Proof of equation (11)

The value function for the problem takes the following form:

$$
V_{t}=\min _{b_{t}} E_{t}\left(i_{t} b_{t}+c_{t}+V_{t+1}\right)
$$

which can be rewritten using the slightly modified expected cost expression (4):

$$
\begin{aligned}
& E_{t}\left(V_{t}\right)=i_{t} b_{t}-i^{l}\left(m_{t}+b_{t}\right) F\left(-m_{t}-b_{t}\right) \\
&-i^{d}\left(m_{t}+b_{t}-d_{t}\right)\left(1-F\left(-m_{t}-b_{t}+d_{t}\right)\right) \\
&-i^{l}\left[\int_{-\infty}^{-m_{t}-b_{t}} \varepsilon_{t} f\left(\varepsilon_{t}\right) d \varepsilon_{t}\right]-i^{d}\left[\int_{-m_{t}-b_{t}+d_{t}}^{\infty} \varepsilon_{t} f\left(\varepsilon_{t}\right) d \varepsilon_{t}\right] \\
&+E V_{t+1}
\end{aligned}
$$

The first order conditions:

$$
i_{t}=i^{l} F\left(-m_{t}-b_{t}\right)+i^{d}\left(1-F\left(-m_{t}-b_{t}+d_{t}\right)\right)+E \frac{\partial V_{t+1}}{\partial b_{t}}
$$


To calculate the last element of the F.O.C. first note that the borrowing maturity is one period, hence it has no direct impact on the asset value and borrowing in the next period. It has, however, impact on the deficiency value, which must be analysed in 3 separate cases:

1. The shock forces the bank to use a lending facility, whereby the deficiency remains unchanged.

2. The shock forces the bank to use a deposit facility, whereby all deficiency gets satisfied.

3. The intermediate case, where the shock value only lowers the deficiency without forcing the bank to use any of the facilities.

In the first two cases, the deficiency either remains unchanged (in comparison with the previous period) or drops to zero, whereby the borrowing decision has no impact on its value.

$$
\begin{aligned}
\int_{-\infty}^{-m_{t}-b_{t}} \frac{\partial V_{t+1}}{\partial b_{t}} f(\varepsilon) d \varepsilon=\int_{-m_{t}+d_{t}-b_{t}}^{\infty} & \frac{\partial V_{t+1}}{\partial b_{t}} f(\varepsilon) d \varepsilon= \\
& \int_{-\infty}^{-m_{t}-b_{t}} \frac{\partial V_{t+1}}{\partial d_{t+1}} \frac{\partial d_{t+1}}{\partial b_{t}} f(\varepsilon) d \varepsilon=0 .
\end{aligned}
$$

In the last case, whenever the deficiency is carried over one period, one more unit of borrowed funds decreases it by the same value, hence,

$$
\begin{aligned}
\int_{-m_{t}-b_{t}}^{-m_{t}-b_{t}+d_{t}} \frac{\partial V_{t+1}}{\partial b_{t}} f(\varepsilon) d \varepsilon=\int_{-m_{t}-b_{t}}^{-m_{t}-b_{t}+d_{t}} & \frac{\partial V_{t+1}}{\partial d_{t+1}} \frac{\partial d_{t+1}}{\partial b_{t}} f(\varepsilon) d \varepsilon= \\
& -\int_{-m_{t}-b_{t}}^{-m_{t}-b_{t}+d_{t}} \frac{\partial V_{t+1}}{\partial d_{t+1}} f(\varepsilon) d \varepsilon
\end{aligned}
$$

leading to profit maximising conditions:

$$
i_{t}=i^{l} F\left(-b_{t}-m_{t}\right)+i^{d}\left[1-F\left(d_{t}-b_{t}-m_{t}\right)\right]-\int_{-m_{t}-b_{t}}^{d_{t}-b_{t}-m_{t}} \frac{\partial V_{t+1}}{\partial d_{t+1}} f(\varepsilon) d \varepsilon .
$$

Proof of equation (12)

The derivative of the value function with respect to deficiency can be solved using an envelope theorem (so the $\left.\frac{\partial V_{t}}{\partial b_{t}}=0\right)$ :

$$
\begin{aligned}
& \frac{\partial V_{t}}{\partial d_{t}}=\frac{\partial}{\partial d_{t}}\left(E\left(c_{t}\right)+E V_{t+1}\right) \\
& \frac{\partial}{\partial d_{t}}\left\{i^{d}\left(m_{t}+b_{t}-d_{t}\right)\left(1-F\left(-m_{t}-b_{t}+d_{t}\right)\right)+i^{d}\left[\int_{-m_{t}-b_{t}+d_{t}}^{\infty} \varepsilon_{t} f\left(\varepsilon_{t}\right) d \varepsilon_{t}\right]\right. \\
& \left.+E V_{t+1}\right\}
\end{aligned}
$$


since the deficiency has no impact on the lending facility use, I only have to analyse the deposit facility probability. That leads to:

$$
\begin{gathered}
\frac{\partial V_{t}}{\partial d_{t}}=i^{d}\left\{-\left(1-F\left(-m_{t}-b_{t}+d_{t}\right)\right)-\left(m_{t}+b_{t}-d_{t}\right) f\left(-m_{t}-b_{t}+d_{t}\right)\right. \\
\left.-\left(-m_{t}-b_{t}+d_{t}\right) f\left(-m_{t}-b_{t}-d_{t}\right)\right\}+E \frac{\partial V_{t+1}}{\partial d_{t}}=-i^{d}\left[1-F\left(-m_{t}-b_{t}+d_{t}\right)\right]+E \frac{\partial V_{t+1}}{\partial d_{t}} .
\end{gathered}
$$

In a manner similar to that above, I analyse 3 cases:

1. The shock forces the bank to use a lending facility, whereby the deficiency remains unchanged.

$$
\frac{\partial d_{t+1}}{\partial d_{t}}=1 \rightarrow \int_{-\infty}^{-m_{t}-b_{t}} \frac{\partial V_{t+1}}{\partial d_{t}} f(\varepsilon) d \varepsilon=\int_{-\infty}^{-m_{t}-b_{t}} \frac{\partial V_{t+1}}{\partial d_{t+1}} f(\varepsilon) d \varepsilon .
$$

2. The shock forces the bank to use a deposit facility, whereby all deficiency gets satisfied so

$$
\frac{\partial d_{t+1}}{\partial d_{t}}=0 \rightarrow \int_{d_{t}-m_{t}-b_{t}}^{\infty} \frac{\partial V_{t+1}}{\partial d_{t}} f(\varepsilon) d \varepsilon=0
$$

3. The intermediate case, where the shock value only lowers the deficiency without forcing the bank to use any of the facilities is similar to case 1.

$$
\frac{\partial d_{t+1}}{\partial d_{t}}=1 \rightarrow \int_{-m_{t}-b_{t}}^{d_{t}-m_{t}-b_{t}} \frac{\partial V_{t+1}}{\partial d_{t}} f(\varepsilon) d \varepsilon=\int_{-m_{t}-b_{t}}^{d_{t}-m_{t}-b_{t}} \frac{\partial V_{t+1}}{\partial d_{t+1}} f(\varepsilon) d \varepsilon
$$

which results in:

$$
\frac{\partial V_{t}}{\partial d_{t}}=-i^{d}\left[1-F\left(d_{t}-b_{t}-m_{t}\right)\right]+\int_{-\infty}^{d_{t}-b_{t}-m_{t}} \frac{\partial V_{t+1}}{\partial d_{t+1}} f(\varepsilon) d \varepsilon .
$$

\section{Proof of the results from section 3.3}

Proof of equation (17):

The equilibrium interest rate at time 2 is given by

$$
\begin{aligned}
i_{2}=i^{l} F\left(-b_{2}-m_{2}\right)+i^{d}[1 & \left.-F\left(d_{2}-b_{2}-m_{2}\right)\right] \\
& +E\left(i_{3}\right)\left[F\left(d_{2}-b_{2}-m_{2}\right)-F\left(-b_{2}-m_{2}\right)\right] .
\end{aligned}
$$


To find the level of liquidity that corresponds to the middle of the corridor system, assume that $i_{2}=E\left(i_{3}\right)=\left(i^{d}+i^{l}\right) / 2$. That implies, $i^{l}-i_{2}=-\left(i^{d}-i_{2}\right)$. Now I can deduct $i_{2}$ from both sides of the equation:

$$
0=\left(i^{l}-i_{2}\right) F\left(-b_{2}-m_{2}\right)+\left(i^{d}-i_{2}\right)\left[1-F\left(d_{2}-b_{2}-m_{2}\right)\right] .
$$

Assuming the shock distribution is symmetric around zero $1-F(\bullet)=F(-\bullet)$ and divided by $\left(i^{l}-i_{2}\right)$

$$
F\left(-b_{2}-m_{2}\right)=F\left(-d_{2}+b_{2}+m_{2}\right),
$$

and finally

$$
m_{2}+b_{2}=\frac{d_{2}}{2}
$$

\section{E Proof of the results from section (5.3)}

Proof of equation (38)

The cost function is given by the following expression:

$$
\operatorname{var}(\text { cost }) \quad \operatorname{var}\left\{i_{t} b_{t}+E\left(c_{t}\right)\right\} \text {. }
$$

Recall that the optimal borrowing in the case of a symmetric corridor system is equal to $b_{t}=m_{t}-d_{t}$. But, in that case, the expected cost reduces to:

$$
\begin{gathered}
E\left(c_{T}\right)=i^{l}\left[\int_{-\infty}^{-m_{T}-b_{T}+d_{T}}\left(-m_{T}-b_{T}+d_{T}-\varepsilon_{T}\right) f\left(\varepsilon_{T}\right) d \varepsilon_{T}\right]- \\
i^{d}\left[\int_{-m_{T}+b_{T}+d_{T}}^{\infty}\left(m_{T}-b_{T}-d_{T}+\varepsilon_{T}\right) f\left(\varepsilon_{T}\right) d \varepsilon_{T}\right] \\
-i^{l}\left[\int_{-\infty}^{0} \varepsilon_{T} f\left(\varepsilon_{T}\right) d \varepsilon_{T}\right]-i^{d}\left[\int_{0}^{\infty} \varepsilon_{T} f\left(\varepsilon_{T}\right) d \varepsilon_{T}\right]= \\
\left(i^{l}-i^{d}\right) \int_{0}^{\infty} \varepsilon_{T} f\left(\varepsilon_{T}\right) d \varepsilon_{T},
\end{gathered}
$$

since

$$
\int_{-\infty}^{0} \varepsilon_{T} f\left(\varepsilon_{T}\right) d \varepsilon_{T}=-\int_{0}^{\infty} \varepsilon_{T} f\left(\varepsilon_{T}\right) d \varepsilon_{T}
$$

so it is a constant non-random value. The cost variance then reduces to:

$$
\begin{array}{r}
\operatorname{var}\left(-i_{t} b_{t}+E\left(c_{t}\right)\right)=\operatorname{var}\left(i_{t}\left(d_{t}-m_{t}\right)+\left(i^{l}-i^{d}\right)\left[\int_{0}^{\infty} \varepsilon_{T} f\left(\varepsilon_{T}\right) d \varepsilon_{T}\right]\right)= \\
\left(d_{t}-m_{t}\right)^{2} \operatorname{var}\left(i_{t}\right) .
\end{array}
$$




\section{F Proof of the equation used in the simulation}

In the simulation study, the following result greatly simplifies the complexity of the computations:

$$
\frac{\partial b_{t}}{\partial m_{t}}=-1
$$

for all periods before the end of the maintenance period.

The key equations for the days prior to the end of the RMP are:

$$
i_{t}=\underbrace{i^{l} F\left(-b_{t}-m_{t}\right)}_{1 .}+\underbrace{i^{d}\left[1-F\left(d_{t}-b_{t}-m_{t}\right)\right]}_{2 .}-\underbrace{\int_{-m_{t}-b_{t}}^{d_{t}-b_{t}-m_{t}} \frac{\partial V_{t+1}}{\partial d_{t+1}} f\left(\varepsilon_{t}\right) d \varepsilon_{t}}_{3 .}
$$

$$
\frac{\partial V_{t}}{\partial d_{t}}=-i^{d}\left[1-F\left(d_{t}-b_{t}-m_{t}\right)\right]+\int_{-\infty}^{d_{t}-b_{t}-m_{t}} \frac{\partial V_{t+1}}{\partial d_{t+1}} f\left(\varepsilon_{t}\right) d \varepsilon_{t}
$$

In all of these equations, the terms $b_{t}$ and $m_{t}$ appear only as a pair $\left(b_{t}+m_{t}\right)$. That means, however, that the derivative is

$$
\frac{\partial i_{t}}{\partial m_{t}}=\frac{\partial i_{t}}{\partial b_{t}}
$$

Hence, the application of the implicit theorem yields:

$$
\frac{\partial b_{t}}{\partial m_{t}}=-\frac{\frac{\partial i_{t}}{\partial m_{t}}}{\frac{\partial i_{t}}{\partial b t}}=-1
$$




\section{References}

Bartolini, L., Bertola, G., Prati, A., July 2001. Banks' reserve management, transaction costs, and the timing of federal reserve intervention. Journal of Banking and Finance 25 (7), 1287-1317.

Clouse, J. A., Dow Jr., J. P., 2002. A computational model of banks' optimal reserve management policy. Journal of Economic Dynamics and Control 26, $1787-1814$.

Hamilton, J. D., February 1996. The daily market for federal funds. The Journal of Political Economy 104 (1), 26-56.

Hamilton, J. D., 1997. Measuring the liquidity effect. American Economic Review 87 (1), 80-97.

Kempa, M., 2006. Money market volatility - a simulation study. Bank of Finland Discussion Paper (13).

Moschitz, J., September 2004. The determinants of the overnight interest rate in the euro area. Working Paper Series 393, European Central Bank.

Pérez-Quirós, G., Rodríguez-Mendizábal, H., February 2006. The daily market for funds in europe:what has changed with the emu. Journal of Money, Credit and Banking 38 (1), 91-118.

Poole, W., December 1968. Commercial bank reserve management in a stochastic model: implications for monetary policy. Journal of Finance 23 (5), 769-791.

Thornton, D. L., 2001. Identifying the liquidity effect at the daily frequency. Federal Reserve Bank of St. Louis Review 83 (4), 59-78.

Välimäki, T., 2003. Fixed rate tenders and the overnight money market equilibrium. Ph.D. thesis, Helsinki School of Economics and Bank of Finland.

Välimäki, T., 2006. Why the marginal mro rate exceeds the ecb policy rate? Discussion Papers 20, Bank of Finland.

Würtz, F., 2003. A comprehensive model of the euro overnight rate. ECB Working Paper 207. 